\title{
Recent Advances in NAMPT Inhibitors: A Novel Immunotherapic Strategy
}

\author{
Ubaldina Galli ${ }^{1}$, Giorgia Colombo ${ }^{1}$, Cristina Travelli ${ }^{2}$, Gian Cesare Tron ${ }^{1}$, \\ Armando A. Genazzani ${ }^{1}$ and Ambra A. Grolla ${ }^{1 *}$
}

${ }^{1}$ Department of Pharmaceutical Sciences, University of Piemonte Orientale, Novara, Italy, ${ }^{2}$ Department of Pharmaceutical Sciences, University of Pavia, Pavia, Italy

Nicotinamide adenine dinucleotide (NAD) is a cofactor of many enzymatic reactions as well as being a substrate for a number of NAD-consuming enzymes (e.g., PARPS, sirtuins, etc). NAD can be synthesized de novo starting from tryptophan, nicotinamide, nicotinic acid, or nicotinamide riboside from the diet. On the other hand, the nicotinamide that is liberated by NAD-consuming enzymes can be salvaged to re-form NAD. In this former

OPEN ACCESS

Edited by:

Gianluigi Lauro,

University of Salerno, Italy

Reviewed by:

Valentina Audrito,

University of Turin, Italy

Santina Bruzzone,

University of Genoa, Italy

Takashi Nakagawa,

University of Toyama, Japan

*Correspondence:

Ambra A. Grolla

ambra.grolla@uniupo.it

Specialty section: This article was submitted to Translational Pharmacology, a section of the journal Frontiers in Pharmacology

Received: 31 January 2020 Accepted: 22 April 2020 Published: 12 May 2020

Citation: Galli U, Colombo G, Travelli C, Tron GC, Genazzani AA and Grolla AA (2020) Recent Advances

in NAMPT Inhibitors: A Novel Immunotherapic Strategy.

Front. Pharmacol. 11:656. doi: 10.3389/fphar.2020.00656 instance, nicotinamide phosphoribosyltransferase (NAMPT) is the bottleneck enzyme. In the many cells in which the salvage pathway is predominant, NAMPT, therefore, represents an important controller of intracellular NAD concentrations, and as a consequence of energy metabolism. It is, therefore, not surprising that NAMPT is over expressed by tumoral cells, which take advantage from this to sustain growth rate and tumor progression. This has led to the initiation of numerous medicinal chemistry programs to develop NAMPT inhibitors in the context of oncology. More recently, however, it has been shown that NAMPT inhibitors do not solely target the tumor but also have an effect on the immune system. To add complexity, this enzyme can also be secreted by cells, and in the extracellular space it acts as a cytokine mainly through the activation of Toll like Receptor 4 (TLR4), although it has not been clarified yet if this is the only receptor responsible for its actions. While specific small molecules have been developed only against the intracellular form of NAMPT, growing evidences sustain the possibility to target the extracellular form. In this contribution, the most recent evidences on the medicinal chemistry of NAMPT will be reviewed, together with the key elements that sustain the hypothesis of NAMPT targeting and the drawbacks so far encountered.

Keywords: nicotinamide adenine dinucleotide, nicotinamide phosphoribosyltransferase, cancer, inflammation, nicotinamide phosphoribosyltransferase inhibitors

\section{INTRODUCTION}

Among the hallmarks of cancer (Hanahan and Weinberg, 2011), re-programming of energy metabolism in a context of higher demand compared to healthy cells (Tennant et al., 2010) is possibly the one that has received the least attention. This is somewhat surprising given that the first data showing that tumoral cells undergo an important metabolic re-programming, switching from 
oxidative phosphorylation to aerobic glycolysis, were reported by the Nobel Prize Winner Otto Warburg over 80 years ago (Pavlova and Thompson, 2016).

Nicotinamide adenine dinucleotide (NAD) is an indispensable electron carrier in cellular energetics in key pathways, including glycolysis, the tricarboxylic acid (TCA) cycle, and oxidative phosphorylation. The higher demand of ATP of cancer cells, together with their metabolic reprogramming, undisputedly leads to a higher demand of $\mathrm{NAD}(\mathrm{P})$. This is further accentuated given that a number of key enzymes, over-expressed or over-activated in cancer, also consume NAD. For example, (i) mono- and poly-ADP ribosyltransferases (including ARTs and PARPs) transfer the ADP ribose moiety to acceptor proteins (Grimaldi and Corda, 2019), (ii) sirtuins catalyze the $\mathrm{NAD}^{+}$-dependent deacetylation of metabolic enzymes and transcription factors, thus controlling metabolism and gene transcription (Kosciuk et al., 2019); and (iii) CD38 uses NAD to generate a number of second messengers, including ADP ribose (ADPR), cyclic ADP ribose (cADPR), and nicotinic acid adenine dinucleotide phosphate (NAADP) (Deaglio et al., 2001). It has been calculated that cellular NAD turnover in cancer cells has a half-life of approximately $1 \mathrm{~h}$ (Rechsteiner et al., 1976).

Cells, and cancer cells in particular, therefore constantly require to replenish the NAD pool and a number of pathways that play this role exist. Mammalian cells can form NAD de novo from dietary precursors: tryptophan, nicotinic acid, nicotinamide or nicotinamide riboside (the biochemistry of NAD synthesis has been reviewed elsewhere; (Chiarugi et al., 2012)). Yet, in many cells, the liberated nicotinamide from NADutilizing enzymes can be re-used in a pathway known as the salvage pathway, and this becomes the predominant manner to maintain NAD levels in many cells. Briefly, nicotinamide phosphoribosyl transferase (NAMPT) catalyzes the synthesis of nicotinamide mononucleotide (NMN) from nicotinamide (NAM) and PRPP (in the presence of ATP). NMN is then converted to NAD by nicotinamide mononucleotide adenylyltransferase (NMNAT). Interestingly, the pathway from nicotinic acid is similar, with nicotinic acid phosphoribosyl transferase (NAPRT) substituting NAMPT.

Given the high turnover of NAD in cancer cells and the fact that NAMPT is the rate-limiting enzyme in the salvage pathway, inhibitors of this enzyme were first reported as possible anticancer agents by Hasmann et al. in 2003, who presented the first specific nanomolar inhibitor of this enzyme, FK866 (also known as APO866; (Hasmann and Schemainda, 2003). At the time, the rationale was mainly supported by the over-expression of NAMPT in cancer cells (a finding which has been reported in numerous cancer types, as reviewed in (Gallí et al., 2010; Galli et al., 2013; Sampath et al., 2015). (Heske et al., 2017; Audrito et al., 2018; Audrito et al., 2019; Lucena-Cacace et al., 2019; Zhu et al., 2019). This has led to a first wave of molecules that entered clinical trials for cancer, with no molecule reported to have progressed to later stages (www.clinicaltrials.gov; Table 1).

FK866, CHS-828 (or GMX-1778), and its pro-drug (GMX1777) were all tested in advanced hematological or solid malignancies, but the lack of significant anti-tumor benefits and the side effects observed dampened the enthusiasm in the field. Yet, this experience and the evidences gathered on NAMPT since have provided new cues onto which develop new drug programs in the field. In the present review, the most recent advances in the medicinal chemistry of NAMPT targeting agents will be presented.

For space limitations, we refer to recent reviews (Montecucco et al., 2013a; Sun et al., 2013; Garten et al., 2015) for most of the background on NAMPT (Figure 1). Yet, we feel important to briefly outline four aspects of these inhibitors that are often overlooked in medicinal chemistry programs: (i) their potential toxicity; (ii) the fact that the target protein is dual-faced, with an intracellular form and an extracellular form that may have different physiopathological roles; (iii) the fact that the tumoral cell might not be the sole target, or the most important target, of these inhibitors in cancer; (iv) the possible role of NAPRT in determining NAMPT inhibitor sensitivity or resistance.

\section{Toxicity of NAMPT Inhibitors}

As mentioned above, toxicity of NAMPT inhibitors proved in clinical trials to be dose-limiting. Trombocytopenia has been the most significant dose-limiting toxicity in patients treated in clinical trials in phases I and II of solid tumors. These evidences were recapitulated in in vivo pre-clinical models and suggest that thrombocytopenia is on-target but occurs only at high doses and that other bone marrow-related toxicities, such as anemia and neutropenia, are also likely (Olesen et al., 2010; Tarrant et al., 2015).

Alongside hematological toxicities, it has been suggested in preclinical studies that retinal toxicity and cardiac toxicity may also be dose-limiting side effects, although this was not reported in the clinical trials (Misner et al., 2017; Cassar et al., 2018). While these have been described as on-target side effects, a recent article from our group somehow suggested that not all NAMPT inhibitors may be endowed with these risks, as we found inhibitors of NAMPT which lacked retinal and cardio-toxicity (Sun et al., 2013). This issue remains to be investigated further and may be due to the physiochemical properties of the compounds (e.g. lipophilicity). Lastly, the possibility that NAMPT inhibitors may induce hepatic steatosis has also been postulated in animal models (Wang et al., 2017), again with no clinical correlate yet.

In conclusion, therefore, the whole of the evidence suggests that toxicity of NAMPT inhibitors as single agents is most likely severe, similar to traditional chemotherapeutic drugs, and therefore regimens that mitigate this should be sought, including the possibility to boost the activity of NAPRT in healthy cells (see below).

\section{NAMPT Is a Dual-Faced Protein: Inside and Outside of Cells}

The initial observations and rational to develop NAMPT inhibitors were based on the role of NAMPT as an intracellular enzyme. Yet, since then, it has been amply shown that NAMPT can be secreted by cells and may act as a cytokine- 


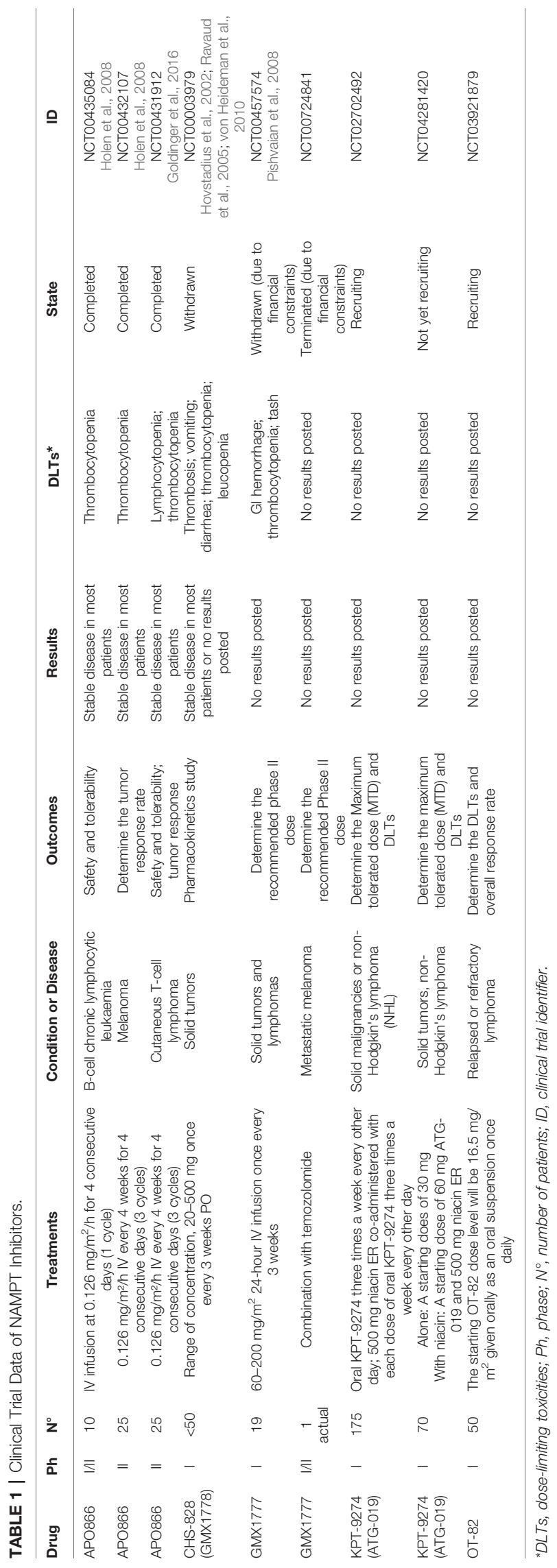

like protein. Whether NAMPT is free in serum or is trapped in microvesicles also requires to be firmly established (Yoshida et al., 2019), and most of the evidences correlating extracellular NAMPT and cancer have been reviewed in Grolla et al. (2016).

Serum NAMPT levels have been shown to be increased and often to correlate with cancer prognosis (reviewed in Galli et al., 2013; Shackelford et al., 2013). The literature strongly sustains a rationale to target also the extracellular protein in cancer and inflammatory diseases. It is likely that this role does not involve the enzymatic activity of the protein, although this is still a controversial issue (Revollo et al., 2007; Hara et al., 2011). Most of these evidences have been reviewed in Grolla et al. (2016) and are summarized in Figure 1.

The exact interplay between the intracellular and extracellular forms has still to be fully clarified, and therefore, it is almost impossible to ascertain whether the effect of the inhibitors so far developed and their potential toxicity can be in part ascribed to the binding to the extracellular form. Furthermore, both appear to be plausible targets in oncology, and approaches can be devised to target only the extracellular form. Novel molecules should, therefore, be designed and characterized for their effect on the intracellular enzymatic activity and/or on the effects of the extracellular form.

\section{Novel Mechanism of Actions of NAMPT Inhibitors}

The most important advance in the field in recent years has been the determination that the intracellular and the extracellular forms of NAMPT are linked to inflammation, and may be directly connected to an effect on the tumor microenvironment. Briefly, NAMPT contributes to myeloid biology, governing monocyte/ macrophage differentiation, polarization, and migration (Travelli et al., 2018). For example, the importance of NAMPT in M1 macrophages is supported by the report that FK866 drives the down-regulation of TNF $\alpha$ and IL-6 expressions. In support of this, Al-Shabany et al. demonstrated that NAD levels are increased in M1-like THP-1 cells and that LPS increases the NAD pool in cells and the relative expression of NAMPT, IDO (indoleamine 2,3-dioxygenase) and CD38, two other key enzymes that govern NAD signaling (Al-Shabany et al., 2016). Interestingly, this is paralleled by the up-regulation of PPAR $\gamma$ and CD163, markers of M2 macrophages (Audrito et al., 2015). Not only macrophages but also T lymphocytes undergo massive NAD depletion upon NAMPT inhibition and, as a consequence, impaired proliferation, reduced IFN $\gamma$ and TNF $\alpha$ production, and eventually autophagic cell demise (Bruzzone et al., 2009). This is supported by the demonstration of how intracellular NAD promotes TNF synthesis by activated immune cells through sirtuin 6 (Van Gool et al., 2009).

A role of NAMPT in inflammation is also supported by the number of reports that have shown an effect of NAMPT inhibitors in inflammatory models (Montecucco et al., 2013b; Camp et al., 2015; Chen et al., 2017; Travelli et al., 2017; Gerner et al., 2018; Franco-Trepat et al., 2019), but is also directly supported by evidences in cancer biology. Indeed, it has been recently reported that myeloid-specific ablation of NAMPT or 




FIGURE 1 | Hallmarks of NAMPT: the roles of the extracellular and intracellular forms of NAMPT.

NAMPT inhibitors themselves prevent myeloid-derived suppressor cell (MDSC) mobilization, reactivated specific antitumor immunity, and enhance the antitumor activity of immune checkpoint inhibitors (Travelli et al., 2019b). Travelli et al. have also demonstrated that in cancer a multistep metabolic process is guided by increased levels of NAMPT, which result in the inactivation of the CXCR4-dependent retention axis and mobilization of suppressor myeloid populations toward tumor immune suppression. All this leads to the observation that the effect of NAMPT inhibitors on tumor growth and metastasis formation is largely independent of an effect on the tumors but is mediated by an effect on the microenvironment. For example, in tumors that are rendered insensitive to NAMPT inhibitors (by mutating the enzyme in such a way that it is unable to bind to these compounds), there is still an important effect of the inhibitors themselves in tumor-bearing mice (Travelli et al., 2019b). In support of this, NAMPT inhibitors enhance the anti-tumor efficacy of immune checkpoint inhibitors (i.e. antibody against PD-1; (Soncini et al., 2014; Travelli et al., $2019 b$ ). This finding modifies substantially the paradigm of the use of NAMPT inhibitors in cancer, as their use is no longer driven solely by the idea of strangling tumoral cells, but is also guided by the possibility of acting on the immune system. Given that this may occur at different concentrations or may require drugs with different physio-chemical properties, it brings new enthusiasm and fuel to the field.

The paradigm may change even further, though, as it is possible that NAMPT is necessary and may be targeted also for other processes. For example, over-expression of NAMPT has been associated to epithelial to mesenchymal transition (EMT) (Soncini et al., 2014). This is supported by a recent report that shows that FK866 is able to inhibit dose-dependently EMT in hepatocarcinoma (Zhang B. et al., 2018). Also, NAMPT has been found involved in tumor-associated angiogenesis. For example, Pylaeva et al. (2019) demonstrated that pro-angiogenic properties of neutrophils depend on the activation of NAMPT signaling pathway in these cells and inhibition of this pathway in tumor-associated neutrophils leads to their potent antiangiogenic phenotype. Lastly, it has been recently shown that NAMPT is critical for the pro-angiogenic activity of tumorassociated neutrophils (TANs). TANs regulate many processes associated with tumor progression, and depending on the microenvironment, they can exhibit pro- or antitumor functions. The authors demonstrated, using transplantable tumor models, that NAMPT is essential for tumorigenic conversion of TANs and their pro-angiogenic switch and inhibition of NAMPT in TANs leads to their antitumor conversion (Pylaeva et al., 2019). All these data, taken together, 
therefore, show that NAMPT inhibitors may be considered dual agents that act on the tumor and on the microenvironment.

Lastly, NAMPT might be up-regulated as a resistance pathway operated by cancer cells, and therefore, NAMPT inhibitors could be used together with other oncological drugs to prolong their efficacy or after these drugs in subsequent lines of therapy. For example, Deaglio's group recently showed that extracellular NAMPT levels were elevated in 113 patients with BRAF-mutated metastatic melanoma compared to 50 with localized disease and to 38 healthy donors, showing a direct correlation with markers of tumor burden, such as LDH or aggressive disease (such as PD-L1). Importantly, NAMPT concentrations decreased in response to therapy with BRAF/ MEK inhibitors, but increased again at progression (Audrito et al., 2018).

\section{NAPRT Is an Important Counterpart to NAMPT in NAD Metabolism}

Potent NAPRT inhibitors have never been developed, and for a long time in the literature, the feeling that this protein might have had a marginal role was predominant. Recent evidences, instead, demonstrate that this is not the case.

The molecular mechanisms that dictate the choice of the NAD synthesis pathway (NAPRT and/or NAMPT) in normal or cancer cells is still not clear. A very recent and extensive work tackled this issue. Chowdhry et al. (2019) analyzed more than 7,000 tumors and 2,600 matched normal samples and found that if NAPRT is highly expressed in a normal tissue type, cancers that arise from that tissue will have a high frequency of NAPRT amplification and most likely will be dependent on NAPRT (Preiss-Handler pathway) for survival. By contrast, non-PreissHandler pathway amplified cancer cell lines depend exclusively on NAMPT and the salvage pathway (Figure 2). To note, cells in the nervous system express almost exclusively NAMPT (DuartePereira et al., 2016) and, therefore, most of the brain tumors are predominantly based on salvage pathway (Chowdhry et al., 2019).

The above observations suggest that there is a strong need for NAPRT inhibitors to be developed and tested, but also that NAMPT inhibitors could be tailored to those tumors in which the Preiss-Handler pathway is irrelevant. Although the article by Chowdhry et al. suggests that dependence on the NAD pathway in cancer arises from tissue lineage-based gene amplification and epigenetic remodeling (Chowdhry et al., 2019), differences among tumors of identical origin are possible (Lee et al., 2018) and, therefore, screening of tumors is still essential. Furthermore, NAMPT-dependent and NAPRT-dependent tumors of the same origin may have different biological features. For example, it has been demonstrated that cell lines and tissues with EMTassociated gene expression signatures express low levels of nicotinic acid phosphoribosyltransferase (NAPRT), which makes these hypersensitive to NAMPT inhibition (Lee et al., 2018).

When the first inhibitors were developed, the role of NAPRT was possibly underestimated. Surprisingly, furthermore, a recent publication has also shown that NAPRT shares the same topological paradox (Managò et al., 2019). Just like NAMPT, extracellular NAPRT enhances monocyte differentiation into macrophages, and these effects are independent of NADbiosynthetic activity (Managò et al., 2019).

All the elements above strongly suggest, therefore, that NAPRT expression should be considered when selecting malignancies that may be susceptible to NAMPT inhibitors. For example, NAPRT is amplified and overexpressed in a subset of common types of cancer, including ovarian cancer, where its expression correlates with a BRCAness gene expression signature.

The interplay between NAMPT inhibitors and NAPRT already has strong foundations (Buonvicino et al., 2018). For example, it has been shown that in cancer cells that lack NAPRT

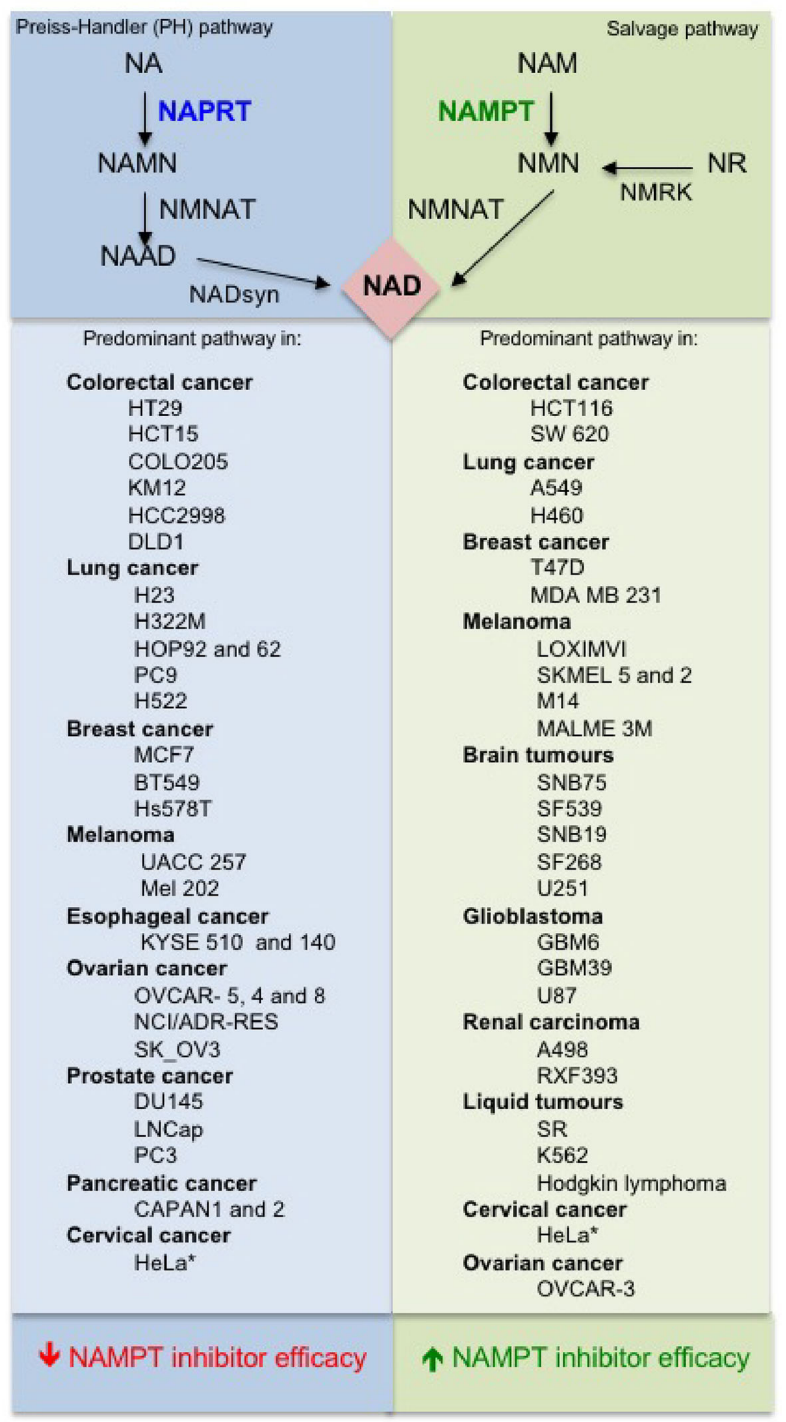

FIGURE 2 | Predominant NAD pathways in different cancer cells (Sociali et al., 2016; Lee et al., 2018; Chowdhry et al., 2019). 
expression (Olesen et al., 2010; Duarte-Pereira et al., 2016) and in which NAD synthesis solely depends on NAMPT, NAMPT inhibitors are significantly more potent. In support of this ability of the two enzymes to vicariate for each other, it has been shown that silencing NAPRT (or inhibiting its activity with 2-hydroxynicotinic acid) sensitizes cells to NAMPT inhibitors (Piacente et al., 2017). Further support is brought by a patent that discloses chemical compounds that inhibit NAPRT activity (including some non-steroidal anti-inflammatory drugs) and sensitize cancer cells to NAMPT inhibitors (Krieg et al., 2013). From a different angle, it has been postulated that more aggressive therapies with NAMPT inhibitors could be envisaged against tumors that solely express NAMPT provided that a supplementation of the therapy with nicotinic acid is provided to boost NAD metabolism in healthy cells, while the tumor would be fully deprived of NAD. This would significantly widen the therapeutic index of NAMPT inhibitors. While this would appear plausible, retinal toxicity was not found diminished when animals were given a NAMPT inhibitor supplemented with nicotinic acid (Zabka et al., 2015). From a different angle, it has been recently described in a patent that chemical compounds that inhibit NAPRT activity (including some non-steroidal anti-inflammatory drugs) sensitize cancer cells to NAMPT inhibitors (Krieg et al., 2013). In this regard, Fons et al. (2019) demonstrated that mutant PPM1D, a protein phosphatase often found truncated in pediatric gliomas, drives hypermethylation of $\mathrm{CpG}$ islands throughout the genome and promotes epigenetic silencing of NAPRT, conferring NAMPT inhibitor sensitivity in glioma and revealing a promising approach for the targeting of PPM1D mutant tumors.

In this context, it should be noticed that quinolinate phosphoribosyltransferase (QPRT), which belongs to the phosphoribosyltransferase family and is involved in de novo NAD biosynthesis using quinolinic acid (QA) as a precursor in both prokaryotes and eukaryotes, has not been thoroughly investigated in the context of cancer and inflammation, but there are evidences that also this enzyme might play a role (Hinsch et al., 2009; Sahm et al., 2013; Ullmark et al., 2017; Haslinger et al., 2018).

In conclusion, therefore, the interplay between NAMPT and NAPRT must be considered when developing novel NAMPT inhibitors, when screening them for activity, when choosing the oncological setting in which to test them, and when attempting to improve their therapeutic index, thereby turning a threat into an opportunity. The possibility of developing non-selective inhibitors, targeting both NAPRT and NAMPT, considering the similarity of the two enzymes, could also be envisaged.

\section{Recent Advances in the Medicinal Chemistry of Intracellular NAMPT Inhibitors}

The seminal discovery that FK866 (1) was able to inhibit NAMPT with a one-digit nanomolar potency (Hasmann and Schemainda, 2003), and the disclosure of the crystal structure of FK866 in complex with the enzyme (Khan et al., 2006) initially boosted this area of research. Two years later, NAMPT was also identified as the principal biological target of the potent cytotoxic agent CHS-828 (2) (Olesen et al., 2008), which had already been described in the literature. Comparison between the two molecules brought to the identification of a common pharmacophoric structure for NAMPT inhibitors based on the topological nature of the binding site. Indeed, the binding site of the enzyme is a tunnel formed by the head to tail dimerization of two NAMPT units. A pyridine (or a pyridine like heterocyclic ring) as cap group mimics and binds at the same position of nicotinamide, the natural substrate of NAMPT. Then, a connecting unit, such as an amide, with the ability to accept hydrogen bonds, is bound to a hydrophobic linker characterized by an appropriate length and geometry able to protrude from the tunnel. Finally, a tail group which juts out over the solventexposed region complete the pharmacophoric model (Figure 3).

These four necessary pieces have been assembled like a legogame by different research teams both in industry and academia giving a cornucopia of potent NAMPT inhibitors with the intent to identify molecules with better ADME properties and/or gaining a leading position in the field of intellectual properties. Structures emerging from this gold rush have been extensively reviewed until 2014. In this manuscript, we would like to review the novel inhibitors that have appeared in the literature or in patents from begin of 2015 until the end of 2019 and for the sake of clarity we have divided the inhibitors in three sub-groups: (i) molecules which follow the typical pharmacophoric model; (ii) molecules which contravene the classical pharmacophore model; (iii) dual hybrids where the NAMPT inhibitory activity is associated with another pharmacological action. We will not consider the antibody-drug conjugates (ADCs) which use
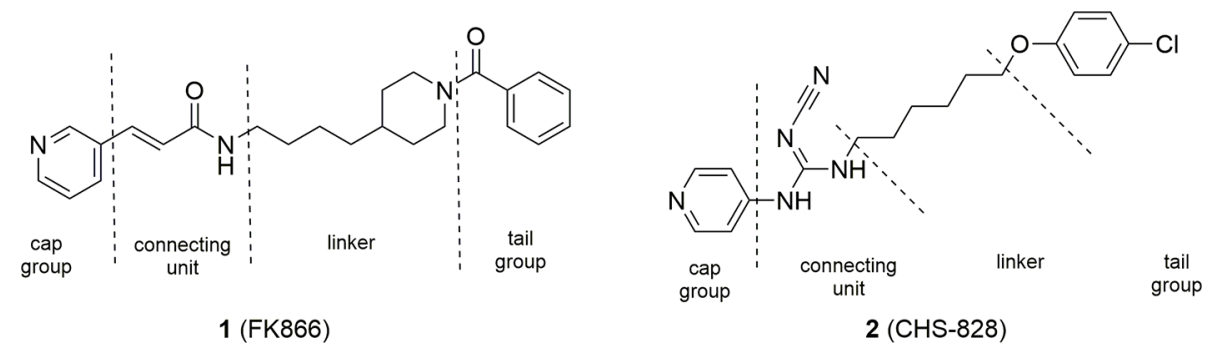

FIGURE 3 | FK866 and CHS-828: the first potent NAMPT inhibitors discovered. 
NAMPT inhibitors as payloads, as this topic has been recently well reviewed (Neumann et al., 2018).

It is important to stress that most of the inhibitors so far described, even the most recent ones, have looked at tumor metabolism as the primary target (thereby overlooking all the other mechanisms), have not tackled the issue of toxicity and have not considered the interplay between NAPRT and NAMPT, thereby falling short of being game changing. Nonetheless, these molecules and the ones that will follow could be excellent tools to tackle these issues. Last, cross-resistance to a diverse set of NAMPT inhibitors has been already reported and demonstrated and therefore warrants for diverse inhibitors to be developed. Different mechanisms are responsible for resistance which include point mutation in the tunnel region, as well as increased expression of quinolate phosphoribosyltransferase an enzyme involved in the de novo NAD synthesis (Guo et al., 2017; Ogino et al., 2018).

\section{Molecules Which Follow the Classic Pharmacophore Model}

After our discovery of the triazolylpyridine GPP78 (3) in 2010 using the click chemistry approach (Colombano et al., 2010), we decided to modify the solvent exposed region of FK866 both to improve the metabolic stability and to target the extracellular form of NAMPT. Metabolic stability was gained inserting nonhydrolysable functional groups in the tail region while selective eNAMPT targeting was tackled by adding a series of polar and ionizable polar groups in the tail region in order to prevent the molecules ability to cross cell membrane. The latter strategy brought to the identification of a series of molecules, namely, compounds 4 and 5, which inhibit the enzyme NAMPT in vitro, lack cell cytotoxicity and are unable to cross the plasma membrane (4: IC $_{50}$ NAMPT $13.6 \pm 2.9$ nM, EC ${ }_{50}$ SH-SY5Y > $1000 \mathrm{nM} ; 5: \mathrm{IC}_{50}$ NAMPT $41.8 \pm 4.1 \mathrm{nM}, \mathrm{EC}_{50}$ SH-SY5Y > 1000 $\mathrm{nM})$. Whether the enzymatic activity of the extracellular form plays any physiological or pathological role is, at present, controversial, and this tool might help those that wish to tackle this issue. On the other hand, $\mathbf{6}$ and 7 were identified as better NAMPT inhibitors with respect to the GPP78. In particular, 7, possibly due to the high polarity, in our hands lacked retinal and cardiac toxicity, possibly suggesting that despite the fact that this is an on-target effect, it may be significantly mitigated. The same compounds were shown to be efficacious in reducing growth of triple negative mammary allograft carcinomas in mice (Travelli et al., 2017; Travelli et al., 2019a) (Figure 4).

With the intention to identify novel tail groups, we again capitalized on the click chemistry approach maintaining a substituted pyridine at the 3 position as cap group and synthesizing molecules with a 1,2,3-triazole ring in the tail position. Due to the high versatility of click chemistry, we were able to synthesize 720 new compounds which were screened for cytotoxicity and for cytotoxicity. This led to the description of a compound ( $\mathrm{EC}_{50}$ of $20 \mathrm{nM}$ for cytotoxicity on SH-SY5Y cells and an $\mathrm{IC}_{50}$ of $100 \mathrm{nM}$ for enzyme inhibition) which bears a novel tail group 8 (Theeramunkong et al., 2015) (Figure 4).

Other authors followed the same reasoning using the trans 3(pyridin-3-yl)acrylamide portion 9 of FK866 as a template for the identification of new NAMPT inhibitors with the variation of the linker and tail group. In particular compound $\mathbf{1 0}$ demonstrated to be very potent, with acceptable in vivo pharmacokinetic properties, being efficient in tumor xenograft models (Bai et al., 2016). As mentioned above, the use of xenografts to characterize these molecules should nonetheless be discouraged, as it does not probe the contribution of the immune system in mediating the effect of NAMPT inhibitors. The same strategy was again applied by the same group which reported a different series of potent NAMPT inhibitors identifying biarylsulfanilamides moieties as tail groups. In particular, compound $\mathbf{1 1}$ was the most potent NAMPT inhibitor identified in this study with an $\mathrm{IC}_{50}$ of $5 \mathrm{nM}$, and

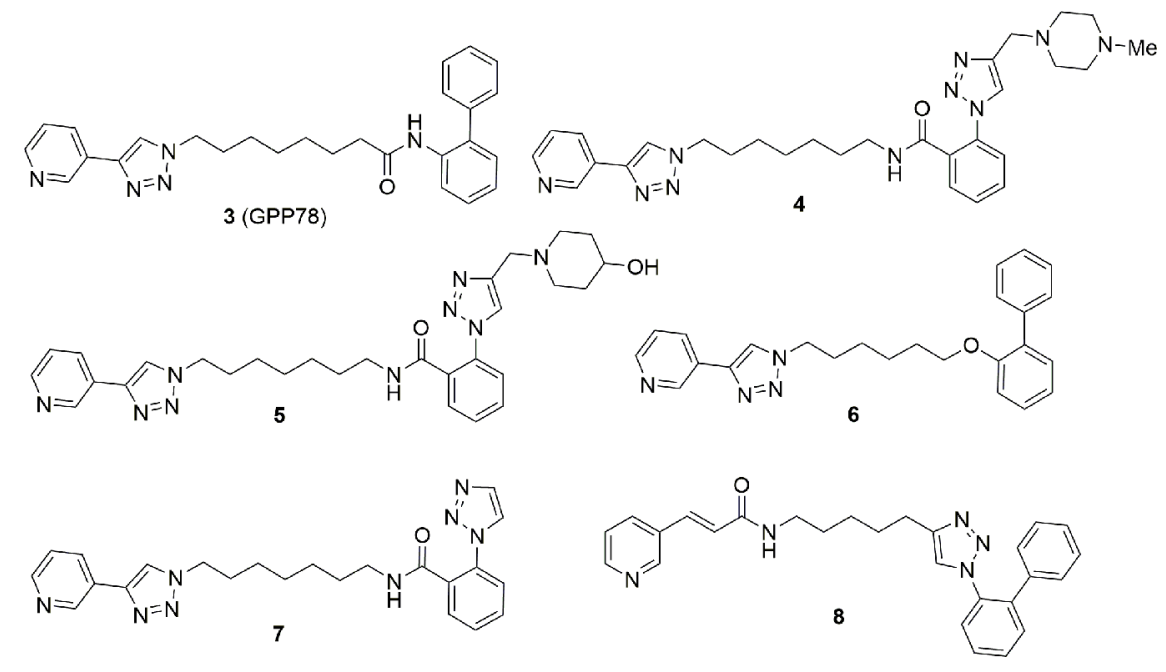

FIGURE 4 | The most important triazole containing molecules as NAMPT inhibitors discovered to date. 
with a potent antiproliferative activity $\left(\mathrm{IC}_{50}\right.$ s between 200 and 2 $\mathrm{nM}$ ) against a number of cell lines (DU145, Hela, H1975, K562, MCF-7, and HUH7) (Zhang et al., 2019) (Figure 5).

Molecules with a dihydropyrrole pyridine as cap group and dihydropyridazinones as tail group exemplified by molecule 12 have also been reported as potent NAMPT inhibitors (Giese et al., 2018) (Figure 6). Patent literature also shows that the cap group can be a nicotinic acid substituted at the 4 position (Tian, 2018a; Tian, 2018b). In the case of the molecule 13, the $\mathrm{IC}_{50}$ on NAMPT inhibition was of around $3 \mathrm{nM}$. Molecules with a more canonical 2,6-dichloropyridine cap group have also been disclosed as potent NAMPT inhibitors (Tian, 2018c). Unfortunately, only the cytotoxic activity on a panel of cancer cell lines was reported for compound $\mathbf{1 4}\left(\mathrm{EC}_{50}\right.$ around $6 \mu \mathrm{g} / \mathrm{mL}$ on K562), and no inhibitory activity on the enzyme has been reported (Figure 6). The data on these compounds must, therefore, be considered with caution until it is proven that they inhibit NAMPT, as in our experience when the positions 2 and 6 of pyridine are substituted with bulky groups (e.g., chlorine and methyl), NAMPT inhibitory activity is abolished (UG and GCT personal communication). It is then possible to speculate that the cytotoxic activity for this compound might be due to the interaction with another pharmacological target.

Structural modifications aimed at simplifying the synthetically complex structure of compound 15 identified through a phenotypic screening (Estoppey et al., 2017) brought to the identification of compound $\mathbf{1 6}$ which, beyond being easily synthetizable, showed a remarkable activity $\left(\mathrm{IC}_{50}=4.2 \mathrm{nM}, \mathrm{EC}_{50}\right.$<smiles>Cc1ccccc1NS(=O)(=O)c1cccc(CCCCCCNC(=O)/C=C/c2cccnc2)c1</smiles>

FIGURE 5 | trans 3-(pyridin-3-y)acrylamide cap group was pivotal for the identification of novel NAMPT inhibitors.<smiles></smiles>

FIGURE 6 | Structure of NAMPT inhibitors discussed in the text. 
$(\mathrm{A} 2780)=7 \mathrm{nM}$ (Palacios et al., 2018) (Figure 6). To note that a 2 -aminopyridine has been used as cap group in order to increase the basicity of the nitrogen atom of pyridine which should potentiate the hydrogen bond between Tyr18 and the nitrogen atom.

Eli-Lilly discovered a novel series of oral available NAMPT inhibitors which are exemplified by compound LSN3154567 (17) which has an $\mathrm{IC}_{50}$ of around $3 \mathrm{nM}$ and a cytotoxic activity of about $10 \mathrm{nM}$ after $24 \mathrm{~h}$ of treatment (Zhao et al., 2017) (Figure 6).

A novel pro-drug strategy named photoactivated chemotherapy (PACT) was used with the intent to increase the water solubility of the NAMPT/GLUT1 inhibitor STF-31 and to reduce its side effects (Lameijer et al., 2017). In brief, two water soluble ruthenium complexes (18 and 19) were prepared using the pyridine nitrogen atom of the cap group as ligand. The main feature of these complexes, that are inactive per se, is that they can be photo dissociated when exposed to a low dose of red light. To note that the use of a red light instead of blue or green light allows for a deeper tissue penetration $(0.5-1.0 \mathrm{~cm})$ being also safer. Being oxygen not required for this photo dissociation, the release of the drug was shown both in normoxia (21\% oxygen) and hypoxia ( $1 \%$ oxygen) conditions. Although these data are still preliminary, this pro-drug strategy appears promising as it compartmentalizes the action of a drug. This could be useful for inflammatory pathologies where NAMPT is overexpressed (Figure 7).

In a recent paper, Authors compared the X-ray binding pose of MS0 (20), a novel NAMPT inhibitor discovered by HTS, with FK866 in order to gain more insights on the molecular binding mode of NAMPT inhibitor for future optimizations. As shown in Figure 8, despite a very similar biological activity $\left(\mathrm{IC}_{50}=9.08\right.$ $\mathrm{nM}$ for MS0 and $\mathrm{IC}_{50}=1.60 \mathrm{nM}$ for FK866), the length of the linker group is very different. If the lack of the hydrogen bond interaction of MS0 with Ser241 is easily rationalizable as thiourea is a poor hydrogen bond hydrogen acceptor compared to amides, the lack of the tail group prevents the formation of pivotal hydrophobic interactions which are useful both to increase affinity and to stabilize the inhibitor (Zhang S. et al., 2018). To note that following lead optimizations of MS0 aimed at

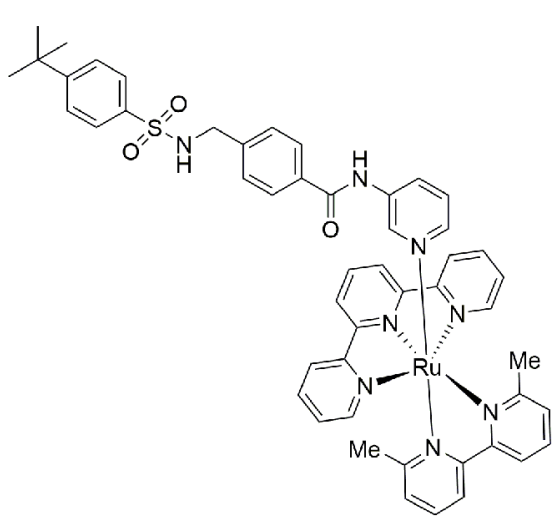

18

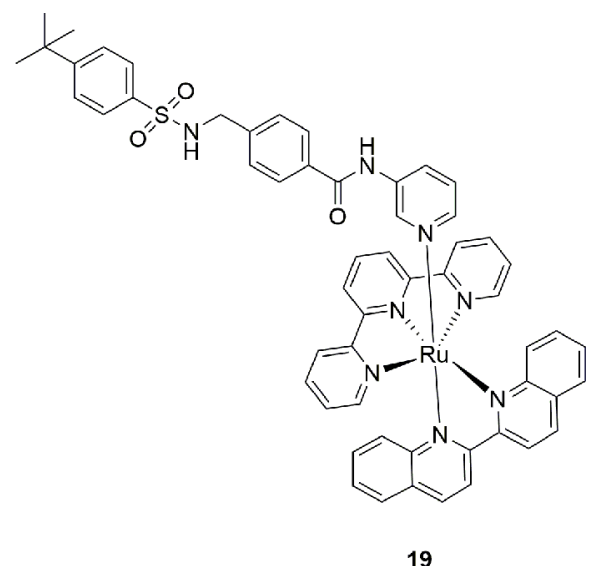

19

FIGURE 7 | Photoactivable pro-drug NAMPT inhibitors.
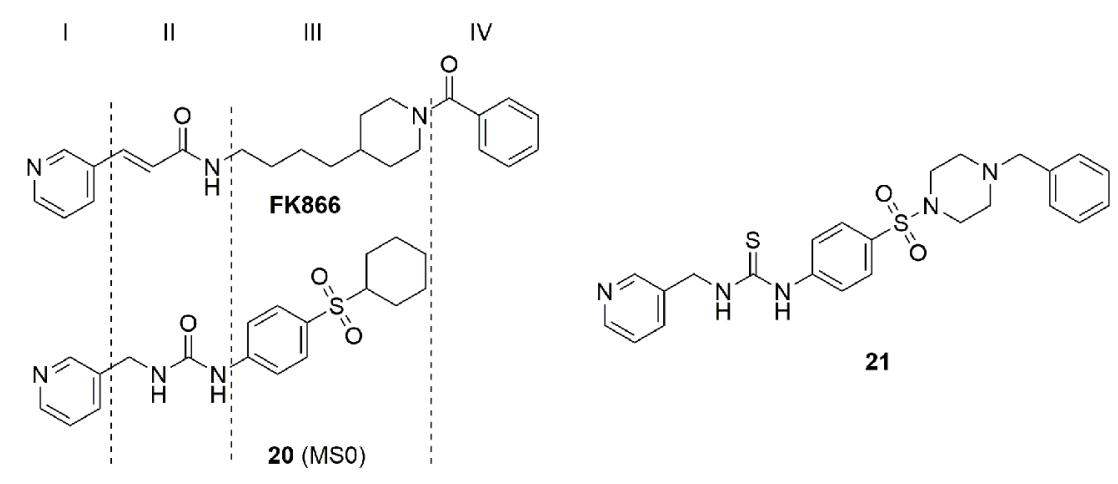

FIGURE 8 | Hydrophobic interaction at the tail group of NAMPT inhibitors are essential for high inhibitory potency. 
increasing the hydrophobic binding interactions on the tail portion of the inhibitor, a more potent inhibitor 21 with an $\mathrm{IC}_{50}$ of $0.93 \mathrm{nM}$ on NAMPT has been described (Xu et al., 2015) (Figure 8).

The presence of a pyridine ring might be problematic due to the well-known ability of the nitrogen atom of pyridine to chelate the iron (II) of heme in several cytochromes. In particular, some NAMPT inhibitors such as $\mathbf{2 2}$ have shown to be potent inhibitors of CYP2C9. Although, for anticancer drugs, lack of inhibition of cytochromes involved in metabolism is not a mandatory requirement to advance to clinic, an industrial group reported how the modification of the linker and the tail group can suppress the inhibitory activity of the pyridine cap group on CYP2C9 retaining the potency as a NAMPT inhibitor (compound 23) (Zak et al., 2016) (Figure 9).

NAMPT inhibitors are characterized not only by cytochrome inhibition but also by scarse aqueous solubility and formation of toxic metabolites. For example, imidazopyridines such as GNE617 (24) can suffer of toxic metabolism, in particular with the formation of reactive glyoxal (Figure 9). For this reason, extra SAR studies have been presented on the potent and previously disclosed NAMPT inhibitor GNE-617 (24). Furthermore, in order to improve aqueous solubility, a strategy to reduce the number of aromatic rings, and consequently, the $\log \mathrm{D}$ has been used. This effort brought to the identification of molecule 25, which is characterized by a good water solubility and no toxic formation of metabolites (Zak et al., 2015) (Figure 9).
Last, from a screening of 3000 molecules as potential NAMPT inhibitors, two molecules (26 and 27) emerged with an in vitro inhibitory activity between 100 and $200 \mathrm{nM}$. Most importantly, the molecule named M049-0244 (27) was fluorescent and might therefore be useful in studies of localization of NAMPT inside and outside cells. Although other fluorescent probes linked to NAMPT inhibitors were already synthesized, the advantage with this class of inhibitors was that the fluorescent portion is also the tail group of the molecule, and this makes these compounds more drug-like compared to other reported probes (Wang et al., 2015) (Figure 10).

\section{Molecules Which Contravene the Classical Pharmacophore Model}

Crystallographic data of FK866 bound to NAMPT indicate that the pyridine ring is in a $\pi$ stacking position between Tyr18 and Phe193, mimicking the position of nicotinamide. Furthermore, the pyridine nitrogen atom is involved in a hydrogen bond with the phenol of Tyr18. These data, along with the pyridine or pyridine-like NAMPT inhibitors discovered to date, seem to corroborate the idea that a pyridine ring as cap group is mandatory for NAMPT inhibition. To note, that the nitrogen atom can also been phosphoribosylated once bound to the enzyme, trapping the molecule inside the cell and boosting its biological action (Oh et al., 2014). This phosphoribosylation was thought indispensable to generate potent inhibitors (Sampath et al., 2015).
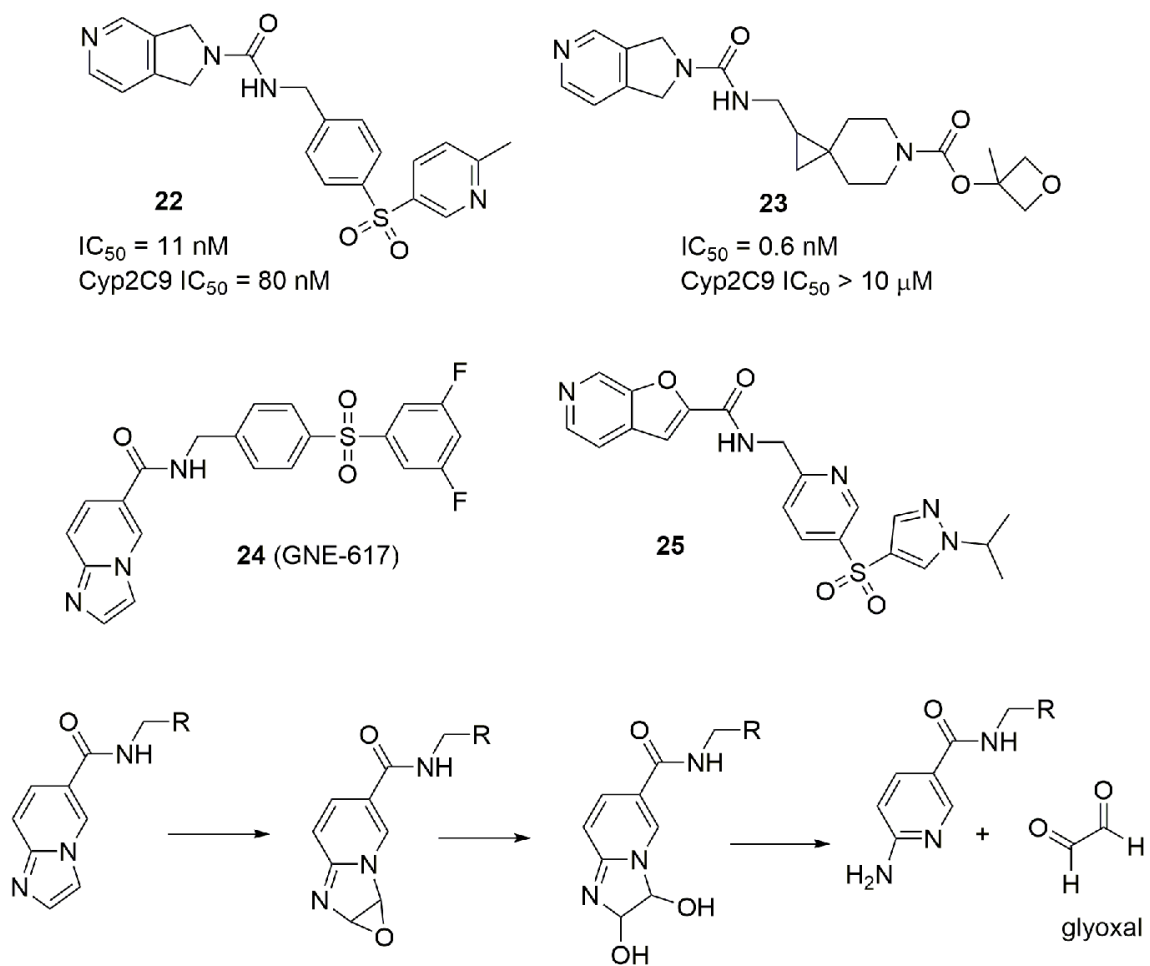

FIGURE 9 | ADME optimization on potent NAMPT inhibitors. 
<smiles>Cc1nc2ccccc2n(Cc2ccc(C(=O)NCc3cccnc3)cc2)c1=O</smiles>

FIGURE $\mathbf{1 0}$ | Compound $\mathbf{2 7}$ is a potent and fluorescent NAMPT inhibitor.<smiles>CCCn1c(=O)c(-c2ccc(C(=O)NCc3cccnc3)cc2)nc2ccccc21</smiles>

Over the last years, this dogma was undermined by the identification of potent NAMPT inhibitors which did not contain a pyridine ring. For example, A-1293201 (28) (Figure 11) is cytotoxic and able to deplete the NAD levels (Guo et al., 2017; Wilsbacher et al., 2017).

This work has two merits: (i) it shows that the phosphoribosylation on the nitrogen atom of pyridine is not mandatory to obtain in vivo cytotoxic NAMPT inhibitors as previously postulated (Oh et al., 2014); (ii) the lack of the pyridine cap group yields molecules able to overcome the Y18C point mutation. Indeed, as previously discussed in this review, the nitrogen atom of pyridine acts as a hydrogen bonding acceptor with Tyr18, forming stronger $\pi$-stacking interactions with Tyr18 compared to a phenyl ring. In the $\mathrm{Y} 18 \mathrm{C}$ point mutation, no $\pi$ stacking interactions are possible as tyrosine has been replaced with a cysteine with negative consequences on the binding affinity for those inhibitors for which the affinity mostly depends on $\pi$ stacking interaction. To note that the crystallographic pose between A-1293201 and the wild type enzyme shows how the isoindoline ring occupies the nicotinamide binding site, and it is parallel to Tyr18 participating in a weak $\pi$ stacking interaction counterbalanced by an extra hydrogen bond between the enzyme and the distal secondary amide.

Combining the fragment-based and structure base strategy other NAMPT inhibitors have also been identified (Korepanova et al., 2018). In brief, six fragment binders (2934) (Figure 12) with an activity between 8 and $1000 \mu \mathrm{M}$ were identified using NMR and TR-FRET techniques. Two of these were then successfully crystalized with NAMPT, while the other four were docked. The comparison of their binding

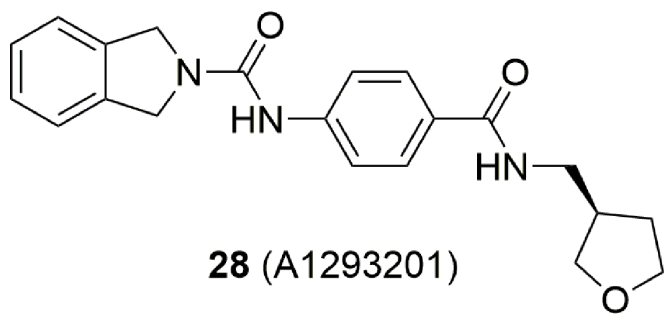

FIGURE 11 | Pyridine cap group is not necessary to obtain potent NAMPT inhibitors. poses with those of FK866, led then to the design of compound 35 which has $\mathrm{IC}_{50}$ of $80 \mathrm{nM}$ on the enzyme (Figure 12). It is interesting to note that apart molecules 31 and 32 which possess a pyridine cap group, the others present a different cap group. The crystallographic poses of $\mathbf{3 0}$ and $\mathbf{3 3}$ indicate the possibility that the binding pocket can accommodate a phenyl ring at the same position of pyridine. The most potent identified compound bears a benzoimidazole cap group and docking studies demonstrated that the nitrogen atom of this heterocycle nicely overlays with the nitrogen atom of pyridine.

In the high throughput campaign that led to the identification of MS0 (20), that falls in the classical NAMPT inhibitor structure, other molecules endowed with NAMPT inhibitory activity not correlated with classical NAMPT inhibitors were identified (36-40). Although the lack of the pyridine cap group reduces the efficiency, they still maintain potency and might be considered as novel lead compounds for optimization (Xu et al., 2015) (Figure 13).

Imidazole has been used as a bioisosteric replacement of pyridine in two patents (Gigstad et al., 2015; Freeze et al., 2016), represented with the structures 41 and 42 in Figure 14. While no direct inhibitory data are available for each compound, the authors stated that many of them possess an $\mathrm{IC}_{50}$ under $10 \mathrm{nM}$.

Lack of structural information makes it difficult to speculate whether the imidazole behaves as a cap or a tail group. Chemical manipulation of 36 brought to the identification of compound 43 with an $\mathrm{IC}_{50}=170 \mathrm{nM}$ and an in vitro antitumor activity of $4 \mu \mathrm{M}$ on HepG2 cancer cell line (Chen et al., 2016). Binding studies suggest that both $\mathbf{3 6}$ and $\mathbf{4 3}$ have a similar binding mode with FK866. In particular the (benzo)thiophene group intercalates between Phe193 and Tyr18, while the amide group is involved in an hydrogen bonding interaction with Ser275. Imidazole is directed toward the solvent exposed region being furthermore involved with a hydrogen bond with His191 (Figure 14).

Very recently Korotchkina et al. (2020) conducted a systematic search for novel agents selectively toxic to cells of hematopoietic origin. Chemical library screenings followed by hit-to-lead optimization identified OT-82 (44) (Figure 14), a small molecule characterized by a pyrazole group. The spectrum of OT-82 cytotoxicity was determined in vitro toward human cell lines derived from 12 hematological malignancies and 17 nonhematological malignancies cancers.

The average $\mathrm{IC}_{50}$ for OT-82 was significantly higher in nonhematological malignancies cancer cells compared with 
<smiles>Cc1ccc(Cn2nnc3cc(C(N)=O)ccc32)cc1</smiles><smiles>CCCc1cc(=O)[nH]c(Nc2ccccc2F)n1</smiles>

$30\left(\mathrm{IC}_{50}=360 \mu \mathrm{M}\right)$<smiles>O=C(NCc1ccncc1)Nc1ccc(F)c(F)c1</smiles>

$31\left(\mathrm{IC}_{50}=850 \mu \mathrm{M}\right)$<smiles>O=C1C2CCC2C(=O)N1CCc1ccccn1</smiles><smiles>O=C1OCCCC1=CNc1ccccc1</smiles>

$33\left(\mathrm{IC}_{50}=10 \mu \mathrm{M}\right)$<smiles>O=C(Cc1ccccc1)Nc1ccc2nc[nH]c2c1</smiles>

$34\left(\mathrm{IC}_{50}=90 \mu \mathrm{M}\right)$<smiles>CC(C)CCNC(=O)c1ccc(NC(=O)Nc2ccc3nc[nH]c3c2)cc1</smiles>

FIGURE 12 | Fragment and structure base strategies allowed the identification of potent NAMPT inhibitors.<smiles>COc1ccc(CCNC(=O)c2cc3ccccc3s2)cc1OCC(CC(C)C)C(=O)c1cccs1</smiles><smiles>O=C1C[C@@H](c2ccc(O)cc2)Oc2c(O)cc(O)c(CC[C@H]3C(=O)c4c(O)cc(O)cc4O[C@H]3c3ccc(O)cc3)c21</smiles>

$40\left(\mathrm{IC}_{50}=504 \mathrm{nM}\right)$

FIGURE 13 | NAMPT inhibitors discovered via HTS

hematological malignancies cancer cells $(13.03 \pm 2.94 \mathrm{nM}$ vs $2.89 \pm 0.47 \mathrm{nM})$.

In toxicological studies conducted in mice and non-human primates, OT-82 showed no cardiac, neurological or retinal toxicities observed with other NAMPT inhibitors. Hematopoietic and lymphoid organs were identified as the primary targets for dose limiting toxicity of OT-82 in both species. These results reveal strong dependence of neoplastic 

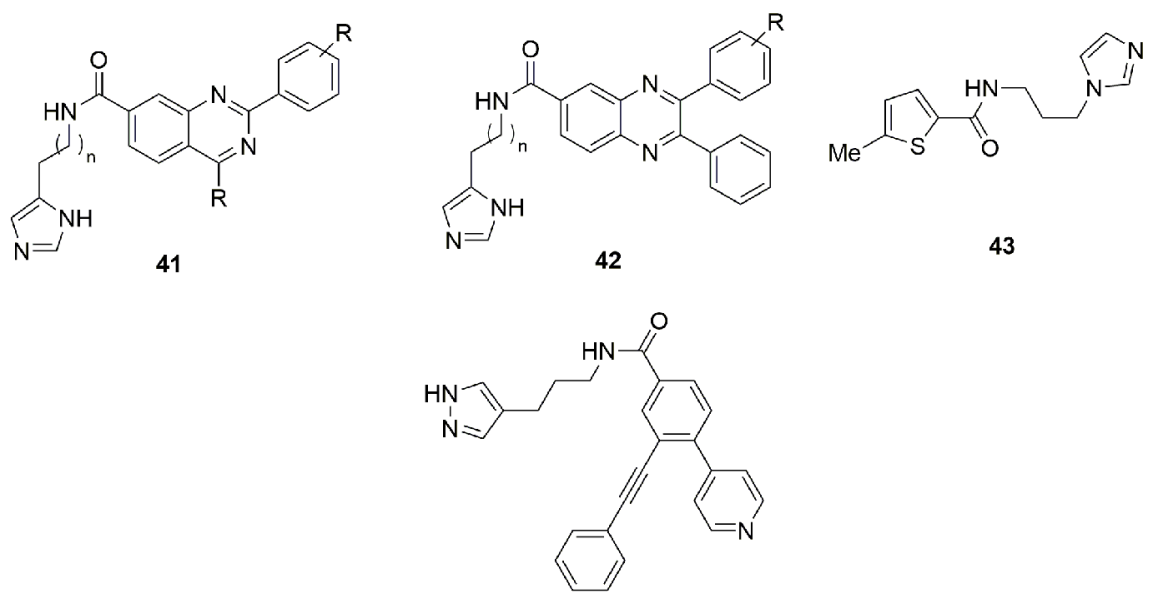

$44(\mathrm{OT}-82)$

FIGURE 14 | Imidazole/pyrazole group is a pharmacophoric element mandatory for this class of NAMPT inhibitors.

cells of hematopoietic origin on NAMPT and introduce OT-82 as a promising candidate for the treatment of hematological malignancies (Korotchkina et al., 2020). A new clinical trial (NCT03921879) is now recruiting patients for OT-82 evaluation for relapsed and refractory lymphoma (Table 1).

\section{Dual Inhibitors}

There is a strong rationale to believe that NAMPT inhibitors might render better if in conjunction with other drugs, reducing the metabolic ability, and therefore the defense potential of cancer cells. For example, the combination between a NAMPT and a PARP inhibitor has been shown to synergize increasing the DNA damage and apoptosis of cells (Heske et al., 2017). The possibility to capitalize on a tool that weakens cells by reducing its metabolism in combination with agents that present a different mechanism of action has been investigated by numerous Authors, as depicted in Table 2.

Given the efficacy of drug combinations, a strategy that has been pursued in drug development, also to overcome the pharmacokinetic problems linked to the simultaneous use of two drugs, was the synthesis of hybrid molecules able to display two different well-balanced mechanisms of action. The structure of all NAMPT inhibitors discovered to date allows for this type of med chem strategy. Indeed, if the pyridine ring is usually important as cap group to give potent compounds, the chemical nature of the so-called tail group which protrudes outside the enzyme is less mandatory as shown above and therefore amenable to recognize other targets.

STF-31 (45) (Kraus et al., 2018), an intrinsically dual acting drug with an inhibitory activity on NAMPT and GLUT1, and KPT-9274 (or ATG-019) (46) can be considered the archetypical examples of this novel class of compounds. The latter is a dual inhibitor of p21-activated kinase (PAK4) and NAMPT with potent cytotoxic activity on B-ALL cells and with the ability to function in vivo in a xenograft murine model. Several studies are emerging from literature, showing the impressive performance of this compound against a series of solid tumors (Abu Aboud et al., 2016). Importantly, KPT-9274 represents the first NAMPT inhibitor of the second wave to have entered clinical trials, although no data has so far been presented (Table 1). In the Phase I study, the drug is used as a single agent in the presence or absence of nicotinic acid (https://clinicaltrials.gov/ct2/ show/NCT02702492).

Apart from this compound, to date this strategy has been used for the construction of hybrid molecules with NAMPT and IDO-1 inhibitory activity or NAMPT and HDAC inhibitory activity. For example, pharmacophoric group of the IDO-1 inhibitor epacadostat has been joined with pyridine derivatives as cap groups (Jiang et al., 2018). These hybrids (for example, 47-50; Figure 15) showed stronger anti-tumor activity by inhibiting the biosynthesis of $\mathrm{NAD}^{+}$, exhibiting stronger tumor-suppressing activity and promoting $\mathrm{T}$ cell proliferation by inhibiting IDO activity. It should be nonetheless noted that $\mathrm{T}$ cell proliferation has been shown to be also an indirect property of pure NAMPT inhibitors in vivo via the inhibition of MDSC activity (Travelli et al., 2019b).

Finally, two different NAMPT-HDAC hybrid inhibitors have been disclosed by the same research group again using a pharmacophore fusion approach. The rationale for this fusion was the observation that NAMPT inhibitors like FK866 were able to enhance the inhibitory effect of HDACs being synergic in the anticancer effect. In particular compounds $\mathbf{5 1}$ and $\mathbf{5 2}$ proved to be very potent and well-balanced hybrids (Figure 15). Both compounds were evaluated in vivo for their antitumor efficacy in HCT116 tumor xenografts in nude mice showing a remarkable reduction of tumor growth superior with respect to SAHA or FK866 when administered as single therapy. To note that the 
TABLE 2 | Evidences that NAMPT inhibitors may synergize with a number of other agents when used in combination.

\begin{tabular}{|c|c|c|c|c|}
\hline Therapeutic Agent & Mechanism & Cell Lines & Therapeutical effects & Reference \\
\hline Olaparib & PARP inhibitor & $\begin{array}{c}\text { CAL51; HS578T; MDA-MB- } \\
\text { 231; MDA-MB-468; SUM149; } \\
\text { MDA-MB-436 }\end{array}$ & $\begin{array}{c}\text { Sensibilization to olaparib in } \\
\text { TNBC }\end{array}$ & (Bajrami et al., 2012) \\
\hline $\begin{array}{l}\text { AraC } \\
\text { daunorubicin } \\
\text { 1-methyl-3-nitro-1- } \\
\text { nitrosoguanidinium (MNNG) } \\
\text { melphalan }\end{array}$ & $\begin{array}{l}\text { Antimetabolite; } \\
\text { DNA alkylating agent; } \\
\text { PARP activating agent; }\end{array}$ & $\begin{array}{l}\text { THP-1 } \\
\text { K562 }\end{array}$ & $\begin{array}{l}\text { Accelerations of cell death } \\
\text { with AraC e daunorubicin and } \\
\text { potentiation of DNA repair } \\
\text { with MNNG }\end{array}$ & (Pogrebniak et al., 2006) \\
\hline Verapamil & ABCB1-transporter inhibitor & HCT116 & Reduced resistance to FK866 & (Ogino et al., 2018) \\
\hline $\begin{array}{l}\text { Etoposide } \\
\text { cisplatin }\end{array}$ & $\begin{array}{l}\text { Topoisomerase inhibitor; } \\
\text { DNA-alkylating agent }\end{array}$ & SH-SY5Y & $\begin{array}{c}\text { FK866 potentiates DNA } \\
\text { damage of etoposide and } \\
\text { cisplatin accelerates NAD } \\
\text { depletion }\end{array}$ & (Travelli et al., 2011) \\
\hline Anti-PD1 & Checkpoint inhibitor & $\begin{array}{l}\text { MN/MCA1 in NAMPTf/f and } \\
\text { NAMPTf/fLysMCre+/- mice }\end{array}$ & $\begin{array}{c}\text { Enhanced anti-tumor efficacy, } \\
\text { reduced metastasis }\end{array}$ & (Travelli et al., 2019b) \\
\hline TRAIL & $\begin{array}{c}\text { Tumor necrosis factor-related } \\
\text { apoptosis-inducing ligand }\end{array}$ & $\begin{array}{c}\text { Jurkat; PEER; H9; MOLT4; } \\
\text { Namalwa }\end{array}$ & Increased autophagy & (Zoppoli et al., 2010) \\
\hline $\begin{array}{l}\text { EX527, sirtinol, cambinol, } \\
\text { vorinostat, valproic acid, and } \\
\text { butyrate }\end{array}$ & HDAC and sirtuin inhibitors & $\begin{array}{l}\text { Primary AML cells; Jurkat } \\
\text { 697; U937 }\end{array}$ & Antileukemic effect & (Cea et al., 2011) \\
\hline $\mathrm{JPH} 203$ & LDHA inhibitors & CCRF-CEM & Reduced glycolysis and & (Thongon et al., 2018) \\
\hline L-asparaginase & & MDA-MB-231 & $\begin{array}{l}\text { lactate production acquired } \\
\text { with resistance to FK866 }\end{array}$ & \\
\hline Bortezomib & Proteasome inhibitor & $\begin{array}{l}\text { MM.1S } \\
\text { MM1R }\end{array}$ & $\begin{array}{l}\text { Reduction of bortezomib } \\
\text { resistance }\end{array}$ & (Cagnetta et al., 2013) \\
\hline Rituximab & Anti-CD20 & $\begin{array}{c}\text { Burkit lymphoma } \\
\text { Diffuse large B-cell lymphoma }\end{array}$ & $\begin{array}{l}\text { Increase autophagy, } \\
\text { caspase- } 3 \text { activation, } \\
\text { mitochondrial depolarization, } \\
\text { and ROS production }\end{array}$ & (Nahimana et al., 2014) \\
\hline Fractionate radiation & Radiation & $\begin{array}{c}\text { PC3 } \\
\text { LnCap }\end{array}$ & $\begin{array}{l}\text { NAD depletion enhances } \\
\text { radiation response }\end{array}$ & (Zerp et al., 2014) \\
\hline $\begin{array}{l}\text { Cyclosporin-A } \\
\text { verapamil } \\
\text { PGP-4008 }\end{array}$ & Pgp inhibitors & $\begin{array}{c}\text { OCI/AML2, OCI/AML3, HL- } \\
\text { 60, HEL, KG1a, SET1, MV4- } \\
\text { 11, MEC.1, MEC.2, LAMA- } \\
\text { 84, RPMI-8226, Dox40, } \\
\text { Daudi, U937, Raji, SU-DHL1 }\end{array}$ & $\begin{array}{c}\text { Increased anti-tumor effect of } \\
\text { APO866 decreasing } \\
\text { resistance }\end{array}$ & (Cagnetta et al., 2015) \\
\hline$\beta$-lapachone & $\begin{array}{c}\text { Bioactivated by } \mathrm{NAD}(\mathrm{P}) \mathrm{H}: \\
\text { quinone oxidoreductase } 1 \\
(\mathrm{NQO1})\end{array}$ & PDA cells; A549 & Increased cell death & $\begin{array}{l}\text { (Moore et al., 2015; Liu et al., } \\
\text { 2016) }\end{array}$ \\
\hline $\begin{array}{l}\beta \text {-methylene adenosine } 5 \text { '- } \\
\text { diphosphate, APCP }\end{array}$ & CD73 inhibitor & OVCAR-3 cells & $\begin{array}{l}\text { Marked potentiation of FK866 } \\
\text { anticancer effects }\end{array}$ & (Sociali et al., 2016) \\
\hline Gemcitabine & Antimetabolite & PDAC-derived PCCs & Potentiation & (Barraud et al., 2016) \\
\hline LU-DOTATATE & $\begin{array}{c}\text { Radiolabeled somatostatin } \\
\text { analogues }\end{array}$ & GOT1 & Radiosensitivization & (Elf et al., 2017) \\
\hline $5-F U$ & Antimetabolite & $\begin{array}{c}\text { MKN45, SGC7901, and } \\
\text { BGC823 }\end{array}$ & $\begin{array}{c}\text { Suppressed cell migration } \\
\text { and anchorage-independent } \\
\text { growth }\end{array}$ & (Bi et al., 2011) \\
\hline Pemetrexed & Antifolate & $\begin{array}{c}\text { A549 } \\
\text { H1299 }\end{array}$ & $\begin{array}{c}\text { PARP- } 1 \text { activation and anti- } \\
\text { tumoral effect }\end{array}$ & (Chan et al., 2014) \\
\hline Temozolomide & Alkylating agent & $\begin{array}{c}\text { U-251; T98 } \\
\text { Patient-derived glioma line } \\
\text { HT1080 (IDH1R132C) }\end{array}$ & $\begin{array}{l}\text { Increased TMZ-induced } \\
\text { apoptosis and necrosis. }\end{array}$ & $\begin{array}{c}\text { (Feng et al., 2016; Tateishi } \\
\text { et al., 2017) }\end{array}$ \\
\hline
\end{tabular}

The list has been extracted via searches from PubMed and may not be complete.

hybrid molecule $\mathbf{5 2}$ was easily assembled using click chemistry as linker group (Dong et al., 2017; Chen et al., 2018).

\section{Strategies to Target the Extracellular Form of NAMPT}

As mentioned previously, all efforts to develop novel inhibitors fall short of understanding the role that these inhibitors have on the activity of the extracellular form, which might be a target in its own right.
Nonetheless, sole targeting of the extracellular protein has now been attempted via the development of neutralizing antibodies. Garcia (Camp et al., 2015) first introduced this possibility in a model of ventilator-induced inflammatory lung injury, in which, the antibody reduced inflammation in mice and decreased NF- $\mathrm{BB}$ phosphorylation in human lung endothelial cells. In parallel, we started to develop a novel monoclonal antibody (C269) that neutralizes in vitro the cytokine-like 

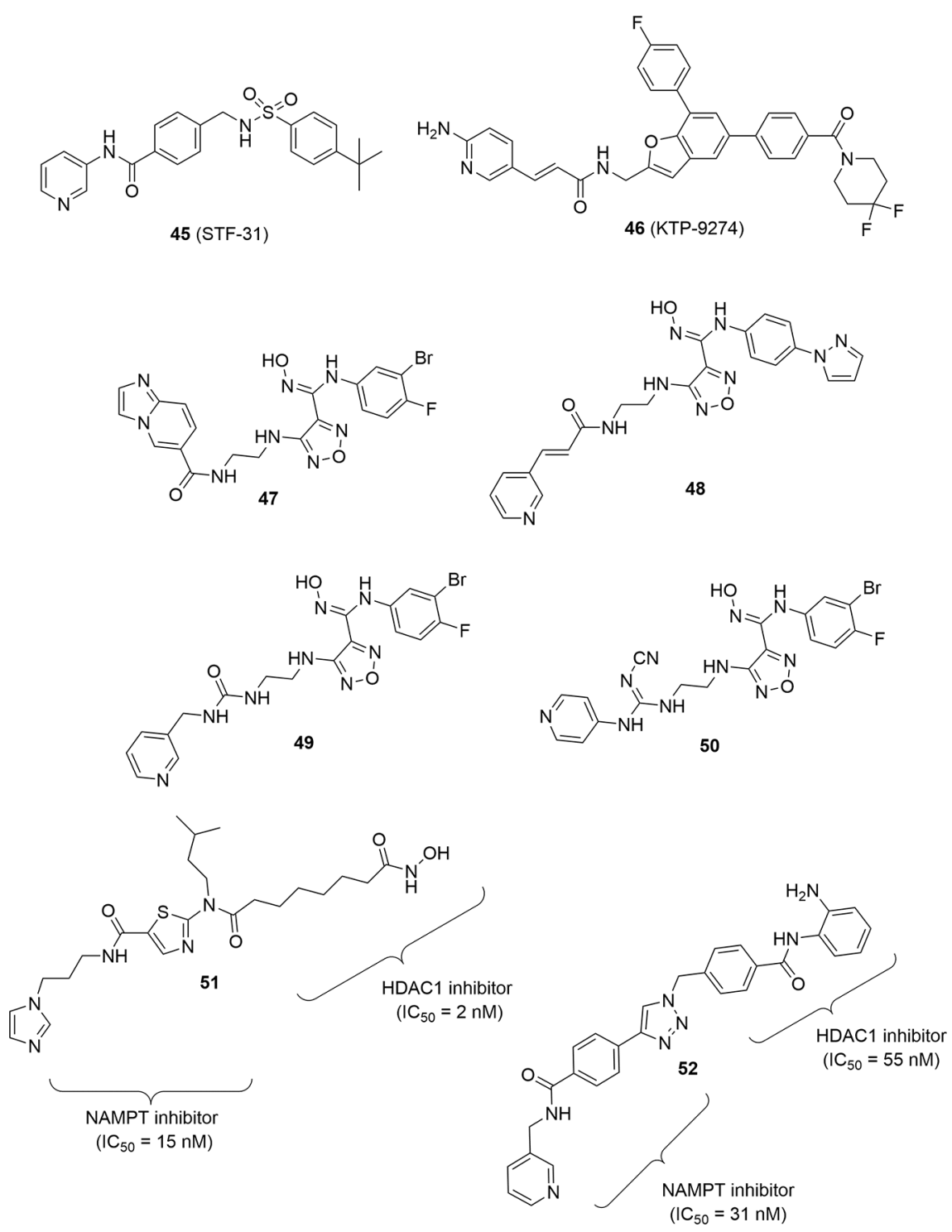

FIGURE 15 | PAK4-NAMPT hybrid inhibitor, IDO1-NAMPT hybrid inhibitors and HDAC-NAMPT hybrid inhibitors.

action of eNAMPT and that reduces its serum levels in rodents. Of note, this newly generated antibody is able to significantly reduce acute and chronic colitis in both DNBS- and dextran sodium sulphate- (DSS) induced colitis (Colombo et al., 2020), demonstrating the eNAMPT participation in inflammatory bowel disease (IBD) and the therapeutic potential of its neutralization in this pathology.

While no data are at present available in cancer, there are ample evidences that the extracellular form is involved (as described above and in (Grolla et al., 2015; Dalamaga et al., 2018; Travelli et al., 2018; Audrito et al., 2019; Ji et al., 2019); and it would be a worthwhile effort to verify its neutralization in this field.

The low levels of PRPP in the extracellular space make it difficult to hypothesize that the enzymatic activity of NAMPT is necessary to extrinsicate its cytokine role, although this might not be true in the tumor microenvironment (because of the presence of necrosis areas) or in vesicles. Recently, indeed, Yoshida demonstrated that eNAMPT is contained exclusively in extracellular vesicles (EVs) in mice and humans and that supplementing eNAMPT in EVs improves physical activity and extends lifespan in mice (Yoshida et al., 2019).

Yet, whether the enzymatic activity is required in the extracellular space has never been formally tested with drugs, due to the difficulty of dissecting the effect of the known NAMPT inhibitors, that freely diffuse across the membrane. Furthermore, also in the plausible case that the enzymatic activity is disposable, it has never been ascertained whether NAMPT-inhibitor complexes still retain their cytokine-like role, as it is possible 
that the conformational changes may modify this. For this reason, Travelli et al. (2019a) first described extracellular inhibitors, incapable of crossing cell membranes due to their polarity (4; Figure 4). While these compounds would be intriguing to investigate the effect of eNAMPT, this has so far not been done. Preliminary unpublished data from our lab has shown a significant toxicity of compound $\mathbf{4}$, that may be reconducted to an unknown off-target effect (although this was not observed with cell-permeable compounds) or might disclose the importance of extracellular NAMPT (CT and GC, personal communication).

\section{CONCLUSION}

The initial hype on NAMPT inhibitors brought to several compounds entering clinical trials. It is possible that such enthusiasm was premature, and more efforts at the time should have been devoted to better understanding the biology of NAMPT. Indeed, it is now emerging that it is much more than a simple workhorse to replenish NAD. The complexity of this enzyme is exemplified by the fact that, while the role as an extracellular cytokine is yet not fully elucidated, it has just emerged that it can also shuttle to the nucleus in cells to provide NMN/NAD on site (Svoboda et al., 2019; Grolla et al., 2020). Although more information has to be gathered, it is now apparent that the hypothesis of using NAMPT inhibitors as a single agent is possibly flawed by the occurrence of side effects. Better, therefore, is the possibility to use it as a combination therapy in which tumors are NAMPT-dependent and in which MDSCs play a role in immune escape. Further biological elements can also be determined: for example, if NAMPT is fundamental for nuclear $\mathrm{NAD}$, then it could be envisaged that PARP inhibitors could be

\section{REFERENCES}

Abu Aboud, O., Chen, C.-H., Senapedis, W., Baloglu, E., Argueta, C., and Weiss, R. H. (2016). Dual and Specific Inhibition of NAMPT and PAK4 By KPT-9274 Decreases Kidney Cancer Growth. Mol. Cancer Ther. 15, 2119-2129. doi: 10.1158/1535-7163.MCT-16-0197

Al-Shabany, A. J., Moody, A. J., Foey, A. D., and Billington, R. D. (2016). Intracellular NAD+ levels are associated with LPS-induced TNF- $\alpha$ release in proinflammatory macrophages. Biosci. Rep. 36, e00301. doi: 10.1042/BSR20150247

Audrito, V., Serra, S., Brusa, D., Mazzola, F., Arruga, F., Vaisitti, T., et al. (2015). Extracellular nicotinamide phosphoribosyltransferase (NAMPT) promotes M2 macrophage polarization in chronic lymphocytic leukemia. Blood 125, 111123. doi: 10.1182/blood-2014-07-589069

Audrito, V., Managò, A., Zamporlini, F., Rulli, E., Gaudino, F., Madonna, G., et al. (2018). Extracellular nicotinamide phosphoribosyltransferase (eNAMPT) is a novel marker for patients with BRAF-mutated metastatic melanoma. Oncotarget 9, 18997-19005. doi: 10.18632/oncotarget.24871

Audrito, V., Managò, A., Gaudino, F., Sorci, L., Messana, V. G., Raffaelli, N., et al. (2019). NAD-Biosynthetic and Consuming Enzymes as Central Players of Metabolic Regulation of Innate and Adaptive Immune Responses in Cancer. Front. Immunol. 10, 1720. doi: 10.3389/fimmu.2019.01720

Bai, J., Liao, C., Liu, Y., Qin, X., Chen, J., Qiu, Y., et al. (2016). Structure-Based Design of Potent Nicotinamide Phosphoribosyltransferase Inhibitors with good therapeutic partners (Bajrami et al., 2012; Heske et al., 2017). This is just a demonstration on how understanding the biology of the protein can increase significantly the efficacy of medicinal chemistry programs. The use of the drug in combination would possibly also reduce toxicity, although it is at present unclear if the immunotherapeutic effect is achieved at similar doses in humans or if dose adjustments are necessary. The choice of dual inhibitors, therefore, appears to go in this direction. Lastly, the possibility to target only the extracellular form of NAMPT, either with antibodies or small chemical entities is intriguing. The last element that should be considered is NAPRT, that is now emerging as a new possible target and for which no specific inhibitors are at present available.

In conclusion, the time is mature to develop and define place in therapies for new NAMPT inhibitors, but their development and characterization should not solely be based on cytotoxicity of tumoral cells or on xenograft models, but should take into account all the lessons learnt so far. This, we hope, will create a new wave of molecules entering clinical trials.

\section{AUTHOR CONTRIBUTIONS}

AmG, UG, and GT proposed, collected information, and wrote the manuscript. GC and CT collected and analyzed the information. ArG supervised the conception and writing of the manuscript.

\section{FUNDING}

The research was supported by an AIRC grant to ArG (AIRC IG2018 21842), by a PRIN grant from the Italian Ministry of Health to ArG (PRIN 2017 CBNCYT).
Promising in Vitro and in Vivo Antitumor Activities. J. Med. Chem. 59, 5766-5779. doi: 10.1021/acs.jmedchem.6b00324

Bajrami, I., Kigozi, A., Van Weverwijk, A., Brough, R., Frankum, J., Lord, C. J., et al. (2012). Synthetic lethality of PARP and NAMPT inhibition in triplenegative breast cancer cells. EMBO Mol. Med. 4, 1087-1096. doi: 10.1002/ emmm.201201250

Barraud, M., Garnier, J., Loncle, C., Gayet, O., Lequeue, C., Vasseur, S., et al. (2016). A pancreatic ductal adenocarcinoma subpopulation is sensitive to FK866, an inhibitor of NAMPT. Oncotarget 7, 53783-53796. doi: 10.18632/ oncotarget.10776

Bi, T.-Q., Che, X.-M., Liao, X.-H., Zhang, D.-J., Long, H.-L., Li, H.-J., et al. (2011). Overexpression of Nampt in gastric cancer and chemopotentiating effects of the Nampt inhibitor FK866 in combination with fluorouracil. Oncol. Rep. 26, 1251-1257. doi: 10.3892/or.2011.1378

Bruzzone, S., Fruscione, F., Morando, S., Ferrando, T., Poggi, A., Garuti, A., et al. (2009). Catastrophic NAD+ depletion in activated T lymphocytes through Nampt inhibition reduces demyelination and disability in EAE. PLoS ONE 4, e7897. doi: 10.1371/journal.pone.0007897

Buonvicino, D., Mazzola, F., Zamporlini, F., Resta, F., Ranieri, G., Camaioni, E., et al. (2018). Identification of the Nicotinamide Salvage Pathway as a New Toxification Route for Antimetabolites. Cell Chem. Biol. 25, 471-482.e7. doi: 10.1016/j.chembiol.2018.01.012 
Cagnetta, A., Cea, M., Calimeri, T., Acharya, C., Fulciniti, M., Tai, Y.-T., et al. (2013). Intracellular $\mathrm{NAD}^{+}$depletion enhances bortezomib-induced antimyeloma activity. Blood 122, 1243-1255. doi: 10.1182/blood-2013-02-483511

Cagnetta, A., Caffa, I., Acharya, C., Soncini, D., Acharya, P., Adamia, S., et al. (2015). APO866 Increases Antitumor Activity of Cyclosporin-A by Inducing Mitochondrial and Endoplasmic Reticulum Stress in Leukemia Cells. Clin. Cancer Res. 21, 3934-3945. doi: 10.1158/1078-0432.CCR-14-3023

Camp, S. M., Ceco, E., Evenoski, C. L., Danilov, S. M., Zhou, T., Chiang, E. T., et al. (2015). Unique Toll-Like Receptor 4 Activation by NAMPT/PBEF Induces NFкB Signaling and Inflammatory Lung Injury. Sci. Rep. 5, 13135. doi: $10.1038 /$ srep 13135

Cassar, S., Dunn, C., Olson, A., Buck, W., Fossey, S., Ramos, M. F., et al. (2018). From the Cover: Inhibitors of Nicotinamide Phosphoribosyltransferase Cause Retinal Damage in Larval Zebrafish. Toxicol. Sci. 161, 300-309. doi: 10.1093/ toxsci/kfx212

Cea, M., Soncini, D., Fruscione, F., Raffaghello, L., Garuti, A., Emionite, L., et al. (2011). Synergistic Interactions between HDAC and Sirtuin Inhibitors in Human Leukemia Cells. PloS One 6, 7. doi: 10.1371/journal.pone.0022739

Chan, M., Gravel, M., Bramoullé, A., Bridon, G., Avizonis, D., Shore, G. C., et al. (2014). Synergy between the NAMPT inhibitor GMX1777(8) and pemetrexed in non-small cell lung cancer cells is mediated by PARP activation and enhanced NAD consumption. Cancer Res. 74, 5948-5954. doi: 10.1158/00085472.CAN-14-0809

Chen, W., Dong, G., He, S., Xu, T., Wang, X., Liu, N., et al. (2016). Identification of benzothiophene amides as potent inhibitors of human nicotinamide phosphoribosyltransferase. Bioorg. Med. Chem. Lett. 26, 765-768. doi: 10.1016/j.bmcl.2015.12.101

Chen, C.-X., Huang, J., Tu, G.-Q., Lu, J.-T., Xie, X., Zhao, B., et al. (2017). NAMPT inhibitor protects ischemic neuronal injury in rat brain via antineuroinflammation. Neuroscience 356, 193-206. doi: 10.1016/ j.neuroscience.2017.05.022

Chen, W., Dong, G., Wu, Y., Zhang, W., Miao, C., and Sheng, C. (2018). Dual NAMPT/HDAC Inhibitors as a New Strategy for Multitargeting Antitumor Drug Discovery. ACS Med. Chem. Lett. 9, 34-38. doi: 10.1021/ acsmedchemlett.7b00414

Chiarugi, A., Dölle, C., Felici, R., and Ziegler, M. (2012). The NAD metabolome-a key determinant of cancer cell biology. Nat. Rev. Cancer 12, 741-752. doi: $10.1038 / \mathrm{nrc} 3340$

Chowdhry, S., Zanca, C., Rajkumar, U., Koga, T., Diao, Y., Raviram, R., et al. (2019). NAD metabolic dependency in cancer is shaped by gene amplification and enhancer remodelling. Nature 569, 570-575. doi: 10.1038/s41586-0191150-2

Colombano, G., Travelli, C., Galli, U., Caldarelli, A., Chini, M. G., Canonico, P. L., et al. (2010). A novel potent nicotinamide phosphoribosyltransferase inhibitor synthesized via click chemistry. J. Med. Chem. 53, 616-623. doi: 10.1021/ jm9010669

Colombo, G., Clemente, N., Zito, A., Bracci, C., Colombo, F. S., Sangaletti, S., et al. (2020). Neutralization of extracellular NAMPT (nicotinamide phosphoribosyltransferase) ameliorates experimental murine colitis. J. Mol. Med. 98, 595-612. doi: 10.1007/s00109-020-01892-0

Dalamaga, M., Christodoulatos, G. S., and Mantzoros, C. S. (2018). The role of extracellular and intracellular Nicotinamide phosphoribosyl-transferase in cancer: Diagnostic and therapeutic perspectives and challenges. Metab. Clin. Exp. 82, 72-87. doi: 10.1016/j.metabol.2018.01.001

Deaglio, S., Mehta, K., and Malavasi, F. (2001). Human CD38: a (r)evolutionary story of enzymes and receptors. Leuk. Res. 25, 1-12. doi: 10.1016/s0145-2126 (00)00093-x

Dong, G., Chen, W., Wang, X., Yang, X., Xu, T., Wang, P., et al. (2017). Small Molecule Inhibitors Simultaneously Targeting Cancer Metabolism and Epigenetics: Discovery of Novel Nicotinamide Phosphoribosyltransferase (NAMPT) and Histone Deacetylase (HDAC) Dual Inhibitors. J. Med. Chem. 60, 7965-7983. doi: 10.1021/acs.jmedchem.7b00467

Duarte-Pereira, S., Pereira-Castro, I., Silva, S. S., Correia, M. G., Neto, C., da Costa, L. T., et al. (2016). Extensive regulation of nicotinate phosphoribosyltransferase (NAPRT) expression in human tissues and tumors. Oncotarget 7, 1973-1983. doi: 10.18632/oncotarget.6538

Elf, A.-K., Bernhardt, P., Hofving, T., Arvidsson, Y., Forssell-Aronsson, E., Wängberg, B., et al. (2017). NAMPT Inhibitor GMX1778 Enhances the
Efficacy of 177Lu-DOTATATE Treatment of Neuroendocrine Tumors. J. Nucl. Med. 58, 288-292. doi: 10.2967/jnumed.116.177584

Estoppey, D., Hewett, J. W., Guy, C. T., Harrington, E., Thomas, J. R., Schirle, M., et al. (2017). Identification of a novel NAMPT inhibitor by CRISPR/Cas9 chemogenomic profiling in mammalian cells. Sci. Rep. 7, 42728. doi: 10.1038/ srep42728

Feng, J., Yan, P.-F., Zhao, H.-Y., Zhang, F.-C., Zhao, W.-H., and Feng, M. (2016). Inhibitor of Nicotinamide Phosphoribosyltransferase Sensitizes Glioblastoma Cells to Temozolomide via Activating ROS/JNK Signaling Pathway. BioMed. Res. Int. 2016, 1450843. doi: 10.1155/2016/1450843

Fons, N. R., Sundaram, R. K., Breuer, G. A., Peng, S., McLean, R. L., Kalathil, A. N., et al. (2019). PPM1D mutations silence NAPRT gene expression and confer NAMPT inhibitor sensitivity in glioma. Nat. Commun. 10, 3790. doi: 10.1038/ s41467-019-11732-6

Franco-Trepat, E., Guillán-Fresco, M., Alonso-Pérez, A., Jorge-Mora, A., Francisco, V., Gualillo, O., et al. (2019). Visfatin Connection: Present and Future in Osteoarthritis and Osteoporosis. J. Clin. Med. 8, 8. doi: 10.3390/ jcm 8081178

Freeze, B., Gigstad, K., Janowick, D., Lee, H., Shi, Z., Soucy, F., et al. (2016). Quinazoline and Quinoline Compounds and Uses Thereof. Available at: https:// patentscope.wipo.int/search/en/detail.jsf?docId=WO2016118565 [Accessed January 9, 2020].

Gallí, M., Van Gool, F., Rongvaux, A., Andris, F., and Leo, O. (2010). The nicotinamide phosphoribosyltransferase: a molecular link between metabolism, inflammation, and cancer. Cancer Res. 70, 8-11. doi: 10.1158/ 0008-5472.CAN-09-2465

Galli, U., Travelli, C., Massarotti, A., Fakhfouri, G., Rahimian, R., Tron, G. C., et al. (2013). Medicinal chemistry of nicotinamide phosphoribosyltransferase (NAMPT) inhibitors. J. Med. Chem. 56, 6279-6296. doi: 10.1021/jm4001049

Garten, A., Schuster, S., Penke, M., Gorski, T., de Giorgis, T., and Kiess, W. (2015). Physiological and pathophysiological roles of NAMPT and NAD metabolism. Nat. Rev. Endocrinol. 11, 535-546. doi: 10.1038/nrendo.2015.117

Gerner, R. R., Klepsch, V., Macheiner, S., Arnhard, K., Adolph, T. E., Grander, C., et al. (2018). NAD metabolism fuels human and mouse intestinal inflammation. Gut 67, 1813-1823. doi: 10.1136/gutjnl-2017-314241

Giese, A., Quanz-Schoeffel, M., Müller, T., Günther, J., Böhnke, N., Griebenow, N., et al. (2018). Dihydropyridazinones Substituted with Phenylureas. Available at: https://patentscope.wipo.int/search/en/detail.jsf?docId=WO2018086703\&rec Num=17\&docAn=EP2016077449\&queryString=EN_ALL:nmr\%20AND\% 20PA:bayer\&maxRec $=10370$ [Accessed January 9, 2020].

Gigstad, K., Cardin, D., Hirayama, T., Hirose, M., Hu, Y., Kakei, H., et al. (2015). Quinoxaline Compounds and Uses Thereof. Available at: https://patentscope. wipo.int/search/en/detail.jsf?docId=WO2015161142 [Accessed January 9, 2020].

Goldinger, S. M., Gobbi Bischof, S., Fink-Puches, R., Klemke, C.-D., Dréno, B., Bagot, M., et al. (2016). Efficacy and Safety of APO866 in Patients With Refractory or Relapsed Cutaneous T-Cell Lymphoma: A Phase 2 Clinical Trial. JAMA Dermatol. 152, 837-839. doi: 10.1001/jamadermatol.2016.0401

Grimaldi, G., and Corda, D. (2019). ADP-ribosylation and intracellular traffic: an emerging role for PARP enzymes. Biochem. Soc Trans. 47, 357-370. doi: 10.1042/BST20180416

Grolla, A. A., Torretta, S., Gnemmi, I., Amoruso, A., Orsomando, G., Gatti, M., et al. (2015). Nicotinamide phosphoribosyltransferase (NAMPT/PBEF/ visfatin) is a tumoural cytokine released from melanoma. Pigment Cell Melanoma Res. 28, 718-729. doi: 10.1111/pcmr.12420

Grolla, A. A., Travelli, C., Genazzani, A. A., and Sethi, J. K. (2016). Extracellular nicotinamide phosphoribosyltransferase, a new cancer metabokine. $\mathrm{Br}$. J. Pharmacol. 173, 2182-2194. doi: 10.1111/bph.13505

Grolla, A. A., Miggiano, R., Di Marino, D., Bianchi, M., Gori, A., Orsomando, G., et al. (2020). A nicotinamide phosphoribosyltransferase-GAPDH interaction sustains the stress-induced NMN/NAD+ salvage pathway in the nucleus. J. Biol. Chem. 295, 3635. doi: 10.1074/jbc.RA119.010571

Guo, J., Lam, L. T., Longenecker, K. L., Bui, M. H., Idler, K. B., Glaser, K. B., et al. (2017). Identification of novel resistance mechanisms to NAMPT inhibition via the de novo NAD+ biosynthesis pathway and NAMPT mutation. Biochem. Biophys. Res. Commun. 491, 681-686. doi: 10.1016/j.bbrc.2017.07.143

Hanahan, D., and Weinberg, R. A. (2011). Hallmarks of cancer: the next generation. Cell 144, 646-674. doi: 10.1016/j.cell.2011.02.013 
Hara, N., Yamada, K., Shibata, T., Osago, H., and Tsuchiya, M. (2011). Nicotinamide Phosphoribosyltransferase/Visfatin Does Not Catalyze Nicotinamide Mononucleotide Formation in Blood Plasma. PloS One 6, e22781. doi: 10.1371/journal.pone.0022781

Haslinger, D., Waltes, R., Yousaf, A., Lindlar, S., Schneider, I., Lim, C. K., et al. (2018). Loss of the Chr16p11.2 ASD candidate gene QPRT leads to aberrant neuronal differentiation in the SH-SY5Y neuronal cell model. Mol. Autism 9, 56. doi: 10.1186/s13229-018-0239-Z

Hasmann, M., and Schemainda, I. (2003). FK866, a highly specific noncompetitive inhibitor of nicotinamide phosphoribosyltransferase, represents a novel mechanism for induction of tumor cell apoptosis. Cancer Res. 63, 7436-7442.

Heske, C. M., Davis, M. I., Baumgart, J. T., Wilson, K., Gormally, M. V., Chen, L., et al. (2017). Matrix Screen Identifies Synergistic Combination of PARP Inhibitors and Nicotinamide Phosphoribosyltransferase (NAMPT) Inhibitors in Ewing Sarcoma. Clin. Cancer Res. 23, 7301-7311. doi: 10.1158/1078-0432.CCR-17-1121

Hinsch, N., Frank, M., Döring, C., Vorländer, C., and Hansmann, M.-L. (2009). QPRT: a potential marker for follicular thyroid carcinoma including minimal invasive variant; a gene expression, RNA and immunohistochemical study. BMC Cancer 9, 93. doi: 10.1186/1471-2407-9-93

Holen, K., Saltz, L. B., Hollywood, E., Burk, K., and Hanauske, A.-R. (2008). The pharmacokinetics, toxicities, and biologic effects of FK866, a nicotinamide adenine dinucleotide biosynthesis inhibitor. Invest. New Drugs 26, 45-51. doi: 10.1007/s10637-007-9083-2

Hovstadius, P., Larsson, R., Jonsson, E., Skov, T., Kissmeyer, A.-M., Krasilnikoff, K., et al. (2002). A Phase I study of CHS 828 in patients with solid tumor malignancy. Clin. Cancer Res. 8, 2843-2850.

Ji, C., Cong, R., Wang, Y., Wang, Y., Zhang, Q., Zhou, X., et al. (2019). Relationship between NAMPT/PBEF/visfatin and prognosis of patients with malignant tumors: a systematic review and meta-analysis. Ann. Transl. Med. 7, 785. doi: 10.21037/atm.2019.11.32

Jiang, S., Hao, H., Guo, C., Wu, X., Yao, H., Zhang, K., et al. (2018). NAMPT and IDO dual target inhibitor, its preparation and applications in cancer treatment. CN108530444A.

Khan, J. A., Tao, X., and Tong, L. (2006). Molecular basis for the inhibition of human NMPRTase, a novel target for anticancer agents. Nat. Struct. Mol. Biol. 13, 582-588. doi: 10.1038/nsmb1105

Korepanova, A., Longenecker, K. L., Pratt, S. D., Panchal, S. C., Clark, R. F., Lake, M., et al. (2018). Fragment-based discovery of a potent NAMPT inhibitor. Bioorg. Med. Chem. Lett. 28, 437-440. doi: 10.1016/j.bmcl.2017.12.023

Korotchkina, L., Kazyulkin, D., Komarov, P. G., Polinsky, A., Andrianova, E. L., Joshi, S., et al. (2020). OT-82, a novel anticancer drug candidate that targets the strong dependence of hematological malignancies on NAD biosynthesis. Leukemia, 1-12. doi: 10.1038/s41375-019-0692-5

Kosciuk, T., Wang, M., Hong, J. Y., and Lin, H. (2019). Updates on the epigenetic roles of sirtuins. Curr. Opin. Chem. Biol. 51, 18-29. doi: 10.1016/j.cbpa.2019.01.023

Kraus, D., Reckenbeil, J., Veit, N., Kuerpig, S., Meisenheimer, M., Beier, I., et al. (2018). Targeting glucose transport and the NAD pathway in tumor cells with STF-31: a re-evaluation. Cell Oncol. (Dordr) 41, 485-494. doi: 10.1007/s13402018-0385-5

Krieg, A. M., Subramanian, R., Mcswiggen, J., and Lee, J. T. (2013). Compositions and methods for modulating apoal and abcal expression. Available at: https:// patents.google.com/patent/WO2013173647A1/en [Accessed January 7, 2020].

Lameijer, L. N., Ernst, D., Hopkins, S. L., Meijer, M. S., Askes, S. H. C., Le Dévédec, S. E., et al. (2017). A Red-Light-Activated Ruthenium-Caged NAMPT Inhibitor Remains Phototoxic in Hypoxic Cancer Cells. Angew. Chem. Int. Ed. Engl. 56, 11549-11553. doi: 10.1002/anie.201703890

Lee, J., Kim, H., Lee, J. E., Shin, S.-J., Oh, S., Kwon, G., et al. (2018). Selective Cytotoxicity of the NAMPT Inhibitor FK866 Toward Gastric Cancer Cells With Markers of the Epithelial-Mesenchymal Transition, Due to Loss of NAPRT. Gastroenterology 155, 799-814.e13. doi: 10.1053/j.gastro.2018.05.024

Liu, H.-Y., Li, Q.-R., Cheng, X.-F., Wang, G.-J., and Hao, H.-P. (2016). NAMPT inhibition synergizes with NQO1-targeting agents in inducing apoptotic cell death in non-small cell lung cancer cells. Chin. J. Nat. Med. 14, 582-589. doi: 10.1016/S1875-5364(16)30068-1

Lucena-Cacace, A., Umeda, M., Navas, L. E., and Carnero, A. (2019). NAMPT as a Dedifferentiation-Inducer Gene: NAD+ as Core Axis for Glioma Cancer StemLike Cells Maintenance. Front. Oncol. 9, 292. doi: 10.3389/fonc.2019.00292
Managò, A., Audrito, V., Mazzola, F., Sorci, L., Gaudino, F., Gizzi, K., et al. (2019). Extracellular nicotinate phosphoribosyltransferase binds Toll like receptor 4 and mediates inflammation. Nat. Commun. 10, 4116. doi: 10.1038/s41467-01912055-2

Misner, D. L., Kauss, M. A., Singh, J., Uppal, H., Bruening-Wright, A., Liederer, B. M., et al. (2017). Cardiotoxicity Associated with Nicotinamide Phosphoribosyltransferase Inhibitors in Rodents and in Rat and Human-Derived Cells Lines. Cardiovasc. Toxicol. 17, 307-318. doi: 10.1007/s12012-016-9387-6

Montecucco, F., Cea, M., Bauer, I., Soncini, D., Caffa, I., Lasigliè, D., et al. (2013a). Nicotinamide phosphoribosyltransferase (NAMPT) inhibitors as therapeutics: rationales, controversies, clinical experience. Curr. Drug Targets 14, 637-643. doi: 10.2174/1389450111314060003

Montecucco, F., Cea, M., Cagnetta, A., Damonte, P., Nahimana, A., Ballestrero, A., et al. (2013b). Nicotinamide phosphoribosyltransferase as a target in inflammation- related disorders. Curr. Top. Med. Chem. 13, 2930-2938. doi: $10.2174 / 15680266113136660208$

Moore, Z., Chakrabarti, G., Luo, X., Ali, A., Hu, Z., Fattah, F. J., et al. (2015). NAMPT inhibition sensitizes pancreatic adenocarcinoma cells to tumorselective, PAR-independent metabolic catastrophe and cell death induced by $\beta$-lapachone. Cell Death Dis. 6, e1599. doi: 10.1038/cddis.2014.564

Nahimana, A., Aubry, D., Breton, C. S., Majjigapu, S. R., Sordat, B., Vogel, P., et al. (2014). The anti-lymphoma activity of APO866, an inhibitor of nicotinamide adenine dinucleotide biosynthesis, is potentialized when used in combination with anti-CD20 antibody. Leuk. Lymphoma 55, 2141-2150. doi: 10.3109/ 10428194.2013.869325

Neumann, C. S., Olivas, K. C., Anderson, M. E., Cochran, J. H., Jin, S., Li, F., et al. (2018). Targeted Delivery of Cytotoxic NAMPT Inhibitors Using AntibodyDrug Conjugates. Mol. Cancer Ther. 17, 2633-2642. doi: 10.1158/15357163.MCT-18-0643

Ogino, Y., Sato, A., Uchiumi, F., and Tanuma, S.-I. (2018). Cross resistance to diverse anticancer nicotinamide phosphoribosyltransferase inhibitors induced by FK866 treatment. Oncotarget 9, 16451-16461. doi: 10.18632/ oncotarget. 24731

Oh, A., Ho, Y.-C., Zak, M., Liu, Y., Chen, X., Yuen, P.-W., et al. (2014). Structural and biochemical analyses of the catalysis and potency impact of inhibitor phosphoribosylation by human nicotinamide phosphoribosyltransferase. Chembiochem 15, 1121-1130. doi: 10.1002/cbic.201402023

Olesen, U. H., Christensen, M. K., Björkling, F., Jäättelä, M., Jensen, P. B., Sehested, M., et al. (2008). Anticancer agent CHS- 828 inhibits cellular synthesis of NAD. Biochem. Biophys. Res. Commun. 367, 799-804. doi: 10.1016/ j.bbrc.2008.01.019

Olesen, U. H., Thougaard, A. V., Jensen, P. B., and Sehested, M. (2010). A preclinical study on the rescue of normal tissue by nicotinic acid in high-dose treatment with APO866, a specific nicotinamide phosphoribosyltransferase inhibitor. Mol. Cancer Ther. 9, 1609-1617. doi: 10.1158/1535-7163.MCT-09-1130

Palacios, D. S., Meredith, E., Kawanami, T., Adams, C., Chen, X., Darsigny, V., et al. (2018). Structure based design of nicotinamide phosphoribosyltransferase (NAMPT) inhibitors from a phenotypic screen. Bioorg. Med. Chem. Lett. 28, 365-370. doi: 10.1016/j.bmcl.2017.12.037

Pavlova, N. N., and Thompson, C. B. (2016). The Emerging Hallmarks of Cancer Metabolism. Cell Metab. 23, 27-47. doi: 10.1016/j.cmet.2015.12.006

Piacente, F., Caffa, I., Ravera, S., Sociali, G., Passalacqua, M., Vellone, V. G., et al. (2017). Nicotinic Acid Phosphoribosyltransferase Regulates Cancer Cell Metabolism, Susceptibility to NAMPT Inhibitors, and DNA Repair. Cancer Res. 77, 3857-3869. doi: 10.1158/0008-5472.CAN-16-3079

Pishvaian, M. J., Marshall, J. L., Hwang, J. H., Malik, S. M., He, A. R., Deeken, J. F., et al. (2008). A phase 1 trial of GMX1777: An inhibitor of nicotinamide phosphoribosyl transferase (NAMPRT). JCO 26, 14568-14568. doi: 10.1200/ jco.2008.26.15_suppl.14568

Pogrebniak, A., Schemainda, I., Azzam, K., Pelka-Fleischer, R., Nüssler, V., and Hasmann, M. (2006). Chemopotentiating effects of a novel NAD biosynthesis inhibitor, FK866, in combination with antineoplastic agents. Eur. J. Med. Res. 11, 313-321.

Pylaeva, E., Spyra, I., Bordbari, S., Lang, S., and Jablonska, J. (2019). Transfer of Manipulated Tumor-associated Neutrophils into Tumor-Bearing Mice to Study their Angiogenic Potential In Vivo. J. Vis. Exp. 144, 136-149. doi: $10.3791 / 59807$ 
Ravaud, A., Cerny, T., Terret, C., Wanders, J., Bui, B. N., Hess, D., et al. (2005). Phase I study and pharmacokinetic of CHS-828, a guanidino-containing compound, administered orally as a single dose every 3 weeks in solid tumours: an ECSG/ EORTC study. Eur. J. Cancer 41, 702-707. doi: 10.1016/j.ejca.2004.12.023

Rechsteiner, M., Hillyard, D., and Olivera, B. M. (1976). Magnitude and significance of NAD turnover in human cell line D98/AH2. Nature 259, 695-696. doi: 10.1038/259695a0

Revollo, J. R., Körner, A., Mills, K. F., Satoh, A., Wang, T., Garten, A., et al. (2007). $\mathrm{Nampt} / \mathrm{PBEF} /$ Visfatin regulates insulin secretion in beta cells as a systemic NAD biosynthetic enzyme. Cell Metab. 6, 363-375. doi: 10.1016/j.cmet.2007.09.003

Sahm, F., Oezen, I., Opitz, C. A., Radlwimmer, B., von Deimling, A., Ahrendt, T., et al. (2013). The endogenous tryptophan metabolite and NAD+ precursor quinolinic acid confers resistance of gliomas to oxidative stress. Cancer Res. 73, 3225-3234. doi: 10.1158/0008-5472.CAN-12-3831

Sampath, D., Zabka, T. S., Misner, D. L., O'Brien, T., and Dragovich, P. S. (2015). Inhibition of nicotinamide phosphoribosyltransferase (NAMPT) as a therapeutic strategy in cancer. Pharmacol. Ther. 151, 16-31. doi: 10.1016/ j.pharmthera.2015.02.004

Shackelford, R. E., Mayhall, K., Maxwell, N. M., Kandil, E., and Coppola, D. (2013). Nicotinamide phosphoribosyltransferase in malignancy: a review. Genes Cancer 4, 447-456. doi: 10.1177/1947601913507576

Sociali, G., Raffaghello, L., Magnone, M., Zamporlini, F., Emionite, L., Sturla, L., et al. (2016). Antitumor effect of combined NAMPT and CD73 inhibition in an ovarian cancer model. Oncotarget 7, 2968-2984. doi: 10.18632/oncotarget.6502

Soncini, D., Caffa, I., Zoppoli, G., Cea, M., Cagnetta, A., Passalacqua, M., et al. (2014). Nicotinamide phosphoribosyltransferase promotes epithelial-tomesenchymal transition as a soluble factor independent of its enzymatic activity. J. Biol. Chem. 289, 34189-34204. doi: 10.1074/jbc.M114.594721

Sun, Z., Lei, H., and Zhang, Z. (2013). Pre-B cell colony enhancing factor (PBEF), a cytokine with multiple physiological functions. Cytokine Growth Factor Rev. 24, 433-442. doi: 10.1016/j.cytogfr.2013.05.006

Svoboda, P., Krizova, E., Sestakova, S., Vapenkova, K., Knejzlik, Z., Rimpelova, S., et al. (2019). Nuclear transport of nicotinamide phosphoribosyltransferase is cell cycle-dependent in mammalian cells, and its inhibition slows cell growth. J. Biol. Chem. 294, 8676-8689. doi: 10.1074/jbc.RA118.003505

Tarrant, J. M., Dhawan, P., Singh, J., Zabka, T. S., Clarke, E., DosSantos, G., et al. (2015). Preclinical models of nicotinamide phosphoribosyltransferase inhibitor-mediated hematotoxicity and mitigation by co-treatment with nicotinic acid. Toxicol. Mech. Methods 25, 201-211. doi: 10.3109/ 15376516.2015.1014080

Tateishi, K., Higuchi, F., Miller, J. J., Koerner, M. V. A., Lelic, N., Shankar, G. M., et al. (2017). The alkylating chemotherapeutic temozolomide induces metabolic stress in IDH1-mutant cancers and potentiates NAD+ depletion-mediated cytotoxicity. Cancer Res. 77, 4102-4115. doi: 10.1158/0008-5472.CAN-16-2263

Tennant, D. A., Durán, R. V., and Gottlieb, E. (2010). Targeting metabolic transformation for cancer therapy. Nat. Rev. Cancer 10, 267-277. doi: $10.1038 / \mathrm{nrc} 2817$

Theeramunkong, S., Galli, U., Grolla, A. A., Caldarelli, A., Travelli, C., Massarotti, A., et al. (2015). Identification of a novel NAMPT inhibitor by combinatorial click chemistry and chemical refinement. Med. Chem. Commun. 6, 1891-1897. doi: 10.1039/C5MD00261C

Thongon, N., Zucal, C., D'Agostino, V. G., Tebaldi, T., Ravera, S., Zamporlini, F., et al. (2018). Cancer cell metabolic plasticity allows resistance to NAMPT inhibition but invariably induces dependence on LDHA. Cancer Metab. 6, 1. doi: 10.1186/s40170-018-0174-7

Tian, L. (2018a). Sulfamide derivative and application thereof in anti-tumour medicament asNAMPT (Nicotinamide Phosphoribosyl Transferase) inhibitor. CN108042539 A 2018.

Tian, L. (2018b). Preparation of the sulfonamide derivative and its application as NAMPT inhibitor in antitumor drugs. CN107987060 A 2018.

Tian, L. (2018c). Sulfonamide derivatives and their use as NAMPT inhibitors. CN108042538 A 2018.

Travelli, C., Drago, V., Maldi, E., Kaludercic, N., Galli, U., Boldorini, R., et al. (2011). Reciprocal potentiation of the antitumoral activities of FK866, an inhibitor of nicotinamide phosphoribosyltransferase, and etoposide or cisplatin in neuroblastoma cells. J. Pharmacol. Exp. Ther. 338, 829-840. doi: 10.1124/ jpet.111.184630
Travelli, C., Aprile, S., Rahimian, R., Grolla, A. A., Rogati, F., Bertolotti, M., et al. (2017). Identification of Novel Triazole-Based Nicotinamide Phosphoribosyltransferase (NAMPT) Inhibitors Endowed with Antiproliferative and Antiinflammatory Activity. J. Med. Chem. 60, 17681792. doi: 10.1021/acs.jmedchem.6b01392

Travelli, C., Colombo, G., Mola, S., Genazzani, A. A., and Porta, C. (2018). NAMPT: A pleiotropic modulator of monocytes and macrophages. Pharmacol. Res. 135, 25-36. doi: 10.1016/j.phrs.2018.06.022

Travelli, C., Aprile, S., Mattoteia, D., Colombo, G., Clemente, N., Scanziani, E., et al. (2019a). Identification of potent triazolylpyridine nicotinamide phosphoribosyltransferase (NAMPT) inhibitors bearing a 1,2,3-triazole tail group. Eur. J. Med. Chem. 181, 111576. doi: 10.1016/j.ejmech.2019.111576

Travelli, C., Consonni, F. M., Sangaletti, S., Storto, M., Morlacchi, S., Grolla, A. A. et al. (2019b). Nicotinamide Phosphoribosyltransferase Acts as a Metabolic Gate for Mobilization of Myeloid-Derived Suppressor Cells. Cancer Res. 79, 1938-1951. doi: 10.1158/0008-5472.CAN-18-1544

Ullmark, T., Montano, G., Järvstråt, L., Jernmark Nilsson, H., Håkansson, E., Drott, K., et al. (2017). Anti-apoptotic quinolinate phosphoribosyltransferase (QPRT) is a target gene of Wilms' tumor gene 1 (WT1) protein in leukemic cells. Biochem. Biophys. Res. Commun. 482, 802-807. doi: 10.1016/ j.bbrc.2016.11.114

Van Gool, F., Gallí, M., Gueydan, C., Kruys, V., Prevot, P.-P., Bedalov, A., et al. (2009). Intracellular NAD levels regulate tumor necrosis factor protein synthesis in a sirtuin-dependent manner. Nat. Med. 15, 206-210. doi: 10.1038/nm.1906

von Heideman, A., Berglund, A., Larsson, R., and Nygren, P. (2010). Safety and efficacy of NAD depleting cancer drugs: results of a phase I clinical trial of CHS 828 and overview of published data. Cancer Chemother. Pharmacol. 65, 11651172. doi: $10.1007 /$ s00280-009-1125-3

Wang, X., Xu, T.-Y., Liu, X.-Z., Zhang, S.-L., Wang, P., Li, Z.-Y., et al. (2015). Discovery of Novel Inhibitors and Fluorescent Probe Targeting NAMPT. Sci. Rep. 5, 12657. doi: 10.1038/srep12657

Wang, L.-F., Wang, X.-N., Huang, C.-C., Hu, L., Xiao, Y.-F., Guan, X.-H., et al. (2017). Inhibition of NAMPT aggravates high fat diet-induced hepatic steatosis in mice through regulating Sirt1/AMPKo/SREBP1 signaling pathway. Lipids Health Dis. 16, 82. doi: 10.1186/s12944-017-0464-z

Wilsbacher, J. L., Cheng, M., Cheng, D., Trammell, S. A. J., Shi, Y., Guo, J., et al. (2017). Discovery and Characterization of Novel Nonsubstrate and Substrate NAMPT Inhibitors. Mol. Cancer Ther. 16, 1236-1245. doi: 10.1158/15357163.MCT-16-0819

Xu, T.-Y., Zhang, S.-L., Dong, G.-Q., Liu, X.-Z., Wang, X., Lv, X.-Q., et al. (2015). Discovery and characterization of novel small-molecule inhibitors targeting nicotinamide phosphoribosyltransferase. Sci. Rep. 5, 10043. doi: 10.1038/ srep10043

Yoshida, M., Satoh, A., Lin, J. B., Mills, K. F., Sasaki, Y., Rensing, N., et al. (2019). Extracellular Vesicle-Contained eNAMPT Delays Aging and Extends Lifespan in Mice. Cell Metab. 30, 329-342.e5. doi: 10.1016/j.cmet.2019.05.015

Zabka, T. S., Singh, J., Dhawan, P., Liederer, B. M., Oeh, J., Kauss, M. A., et al. (2015). Retinal toxicity, in vivo and in vitro, associated with inhibition of nicotinamide phosphoribosyltransferase. Toxicol. Sci. 144, 163-172. doi: $10.1093 /$ toxsci/kfu268

Zak, M., Liederer, B. M., Sampath, D., Yuen, P.-W., Bair, K. W., Baumeister, T., et al. (2015). Identification of nicotinamide phosphoribosyltransferase (NAMPT) inhibitors with no evidence of CYP3A4 time-dependent inhibition and improved aqueous solubility. Bioorg. Med. Chem. Lett. 25, 529-541. doi: 10.1016/j.bmcl.2014.12.026

Zak, M., Yuen, P.-W., Liu, X., Patel, S., Sampath, D., Oeh, J., et al. (2016). Minimizing CYP2C9 Inhibition of Exposed-Pyridine NAMPT (Nicotinamide Phosphoribosyltransferase) Inhibitors. J. Med. Chem. 59, 8345-8368. doi: 10.1021/acs.jmedchem.6b00697

Zerp, S. F., Vens, C., Floot, B., Verheij, M., and van Triest, B. (2014). NAD ${ }^{+}$ depletion by APO866 in combination with radiation in a prostate cancer model, results from an in vitro and in vivo study. Radiother Oncol. 110, 348354. doi: 10.1016/j.radonc.2013.10.039

Zhang, B., Shi, D., Zhang, X., Liang, G., Liu, W., and Qiao, S. (2018). FK866 inhibits the epithelial-mesenchymal transition of hepatocarcinoma MHCC97H cells. Oncol. Lett. 16, 7231-7238. doi: 10.3892/ol.2018.9541 
Zhang, S., Xu, T., Yang, Z.-L., Han, S., Zhao, Q., and Miao, C. (2018). Crystal structure-based comparison of two NAMPT inhibitors. Acta Pharmacol. Sin. 39, 294-301. doi: 10.1038/aps.2017.80

Zhang, K., Ni, Y., Chen, J., Tu, Z., Wu, X., Chen, D., et al. (2019). Discovery of trans-3-(pyridin-3-yl)acrylamide-derived sulfamides as potent nicotinamide phosphoribosyltransferase (NAMPT) inhibitors for the potential treatment of cancer. Bioorg. Med. Chem. Lett. 29, 1502-1506. doi: 10.1016/ j.bmcl.2019.04.013

Zhao, G., Green, C. F., Hui, Y.-H., Prieto, L., Shepard, R., Dong, S., et al. (2017). Discovery of a Highly Selective NAMPT Inhibitor That Demonstrates Robust Efficacy and Improved Retinal Toxicity with Nicotinic Acid Coadministration. Mol. Cancer Ther. 16, 2677-2688. doi: 10.1158/1535-7163.MCT-16-0674

Zhu, Y., Liu, J., Park, J., Rai, P., and Zhai, R. G. (2019). Subcellular compartmentalization of NAD+ and its role in cancer: A sereNADe of metabolic melodies. Pharmacol. Ther. 200, 27-41. doi: 10.1016/ j.pharmthera.2019.04.002
Zoppoli, G., Cea, M., Soncini, D., Fruscione, F., Rudner, J., Moran, E., et al. (2010). Potent synergistic interaction between the Nampt inhibitor APO866 and the apoptosis activator TRAIL in human leukemia cells. Exp. Hematol. 38, 979988. doi: 10.1016/j.exphem.2010.07.013

Conflict of Interest: The authors declare that the research was conducted in the absence of any commercial or financial relationships that could be construed as a potential conflict of interest.

Copyright (c) 2020 Galli, Colombo, Travelli, Tron, Genazzani and Grolla. This is an open-access article distributed under the terms of the Creative Commons Attribution License (CC BY). The use, distribution or reproduction in other forums is permitted, provided the original author(s) and the copyright owner(s) are credited and that the original publication in this journal is cited, in accordance with accepted academic practice. No use, distribution or reproduction is permitted which does not comply with these terms. 